\title{
Charge-sensitive modelling of organic Rankine cycle power systems for off-design performance simulation
}

\author{
Rémi Dickes*, Olivier Dumont, Ludovic Guillaume, Sylvain Quoilin, Vincent Lemort \\ Thermodynamics Laboratory, Faculty of Applied Sciences, University of Liège, Allée de la Découverte 17, B-4000 Liège, Belgium
}

\section{H I G H L I G H T S}

- True off-design models must be charge-sensitive to be fully deterministic.

- To account for the charge helps to identify the heat exchangers coefficients.

- Hugmark's void fraction model shows the best results to simulate two-phase flows.

- The presence of a liquid receiver arises numerical issues to model ORC systems.

- The charge-sensitive model is validated with experimental data.

\section{A R T I C L E I N F O}

\section{Keywords:}

Organic Rankine cycle

Modelling

Off-design

Charge-sensitive

Void fraction

\begin{abstract}
A B S T R A C T
This paper focuses on a charge-sensitive model to characterize the off-design performance of low-capacity organic Rankine cycle (ORC) power systems. The goal is to develop a reliable steady-state model that only uses the system boundary conditions (i.e. the supply heat source/heat sink conditions, the mechanical components rotational speeds, the ambient temperature and the total charge of working fluid) in order to predict the ORC performance. To this end, sub-models are developed to simulate each component and they are assembled to model the entire closed-loop system. A dedicated solver architecture is proposed to ensure high-robustness for charge-sensitive simulations.

This work emphasizes the complexity of the heat exchangers modelling. It demonstrates how state-of-the-art correlations may be used to identify the convective heat transfer coefficients and how the modelling of the charge helps to assess their reliability. In order to compute the fluid density in two-phase conditions, five different void fraction models are investigated. A $2 \mathrm{kWe}$ unit is used as case study and the charge-sensitive ORC model is validated by comparison to experimental measurements. Using this ORC model, the mean percent errors related to the thermal power predictions in the heat exchangers are lower than $2 \%$. Regarding the mechanical powers in the pump/expander and the net thermal efficiency of the system, these errors are lower than $11.5 \%$ and $11.6 \%$, respectively.
\end{abstract}

\section{Introduction}

Among the fields of research and development in the energy sector, power generation from low-grade heat sources is gaining interest because of its enormous worldwide potential [1]. For low-temperature (i.e. below $200^{\circ} \mathrm{C}$ ) or low-capacity applications (typically lower than $2 \mathrm{MWe}$ ), the use of conventional steam power plants is neither technically nor economically beneficial [2]. However, by substituting water with an organic compound as working fluid (WF), it is possible to efficiently convert low-grade heat into mechanical power by means of a closed-loop Rankine cycle. In such a case, the terminology organic
Rankine cycle (ORC) is used to name the system [3]. A common aspect of most ORC power systems is the versatile nature of their operating conditions. Either for combined heat and power, waste heat recovery, geothermal or solar thermal applications, the heat source and the heat sink conditions often vary in time, which forces the ORC system to adapt its working regime for performance or safety reasons. Consequently, once sized and built, an ORC system often operates in conditions differing from its nominal design point.

The study of ORC systems in off-design conditions is not a new topic and numerous papers can be found in the scientific literature. Over the past years, both steady-state and dynamic models have been developed

\footnotetext{
* Corresponding author.

E-mail addresses: rdickes@ulg.ac.be (R. Dickes), olivier.dumont@ulg.ac.be (O. Dumont), ludovic.guillaume@ulg.ac.be (L. Guillaume), squoilin@ulg.ac.be (S. Quoilin), vincent.lemort@ulg.ac.be (V. Lemort).
} 


\begin{tabular}{|c|c|c|c|}
\hline \multicolumn{2}{|c|}{ Nomenclature } & \multicolumn{2}{|c|}{ Variables } \\
\hline \multirow{2}{*}{\multicolumn{2}{|c|}{ Acronyms }} & $\alpha$ & void fraction $(-)$ \\
\hline & & $\beta$ & weighing factor $(-)$ \\
\hline BPHEX & Brazed Plate Heat Exchanger & $\Delta$ & difference $(-)$ \\
\hline $\mathrm{CD}$ & Condenser & $\dot{m}$ & mass flow $(\mathrm{kg} / \mathrm{s})$ \\
\hline $\mathrm{EV}$ & Evaporator & $\dot{Q}$ & heat power $(\mathrm{W})$ \\
\hline EXP & Expander & $\dot{V}$ & volume flow $\left(\mathrm{m}^{3} / \mathrm{s}\right)$ \\
\hline FCHEX & Fin Coil Heat Exchanger & $\dot{W}$ & power (W) \\
\hline HEX & Heat Exchanger & $\eta$ & efficiency (\%) \\
\hline HP & High Pressure & $\mu$ & viscosity $(\mathrm{kg} /(\mathrm{s} \cdot \mathrm{m}))$ \\
\hline HTF & Heat Transfer Fluid & $\omega$ & spatial fraction of a zone $(-)$ \\
\hline LP & Low Pressure & $\rho$ & density $\left(\mathrm{kg} / \mathrm{m}^{3}\right)$ \\
\hline LR & Liquid Receiver & $\theta$ & chevron angle (rad) \\
\hline MAPE & Mean Absolute Percent Error & $A$ & surface $\left(\mathrm{m}^{2}\right)$ \\
\hline NRMSE & Normalized Root Mean Square Error & $B$ & parameter $(-)$ \\
\hline $\mathrm{PP}$ & Pump & $B d$ & bond number $(-)$ \\
\hline REC & Recuperator & Bo & boiling number $(-)$ \\
\hline \multirow[t]{2}{*}{ WF } & Working Fluid & & correction factor $(-)$ \\
\hline & & $D_{h}$ & hydraulic diameter (m) \\
\hline \multirow{2}{*}{\multicolumn{2}{|c|}{ Subscripts }} & $G$ & mass flux $\left(\mathrm{kg} /\left(\mathrm{s} \cdot \mathrm{m}^{2}\right)\right)$ \\
\hline & & $H$ & convective heat transfer coefficient $\left(\mathrm{W} /\left(\mathrm{m}^{2} \cdot \mathrm{K}\right)\right)$ \\
\hline $\mathrm{amb}$ & ambient & $h$ & enthalpy $(\mathrm{J} / \mathrm{kg})$ \\
\hline c & cold & it & iteration variable $(-)$ \\
\hline cs & cross-section & $j$ & colburn factor $(-)$ \\
\hline ex & exhaust & $K$ & parameter (-) \\
\hline exp & experimental & $k$ & conductivity $(\mathrm{W} /(\mathrm{m} \cdot \mathrm{K}))$ \\
\hline h & hot & $L / l$ & length $(\mathrm{m})$ \\
\hline $\mathrm{i}, \mathrm{j}, \mathrm{k}$ & index & $M$ & mass $(\mathrm{kg})$ \\
\hline 1 & saturated liquid & $m$ & Reynolds exponent (-) \\
\hline lam & laminar & $M M$ & molecular weight $(-)$ \\
\hline $\mathrm{lk}$ & leakage & $\mathrm{Nu}$ & Nusselt number (-) \\
\hline $\log$ & logarithmic & $P$ & pressure (Pa, bar) \\
\hline $\max$ & maximum & $\operatorname{Pr}$ & Prandtl number (-) \\
\hline mec & mechanical & $R e$ & Reynolds number (-) \\
\hline $\min$ & minimum & res & residuals $(-)$ \\
\hline sc & subcooling & $r v$ & volume-ratio (-) \\
\hline $\operatorname{sim}$ & simulation & $S$ & slip ratio $(-)$ \\
\hline sp & single-phase & $T$ & temperature $\left(\mathrm{K} /{ }^{\circ} \mathrm{C}\right)$ \\
\hline su & supply & $U$ & global heat transfer coefficient $\left(\mathrm{W} /\left(\mathrm{m}^{2} \cdot \mathrm{K}\right)\right)$ \\
\hline tot & total & $u$ & fluid velocity $(\mathrm{m} / \mathrm{s})$ \\
\hline tp & two-phase & $V$ & volume $\left(\mathrm{m}^{3}\right)$ \\
\hline turb & turbulent & $W e$ & Weber number $(-)$ \\
\hline $\mathrm{v}$ & saturated vapour & $x$ & quality (-) \\
\hline
\end{tabular}

to simulate ORC units under various operations. To illustrate the current state-of-the-art, a non-exhaustive list of thirteen works is presented in Table 1. As highlighted in the last column, almost all the existing models rely on user-defined assumptions in the ORC state, e.g. an imposed fluid subcooling, superheating or condensing pressure. Such hypotheses make the off-design models not fully deterministic and can mislead the performance predictions. For instance, to assume a constant fluid subcooling in the ORC makes the simulations blind to important phenomena susceptible to occur in off-design operations, like the cavitation of the pump or the complete flooding of the liquid receiver. In practice, the state in an ORC system is unequivocally defined by its boundary conditions. All the pressures, temperatures and energy transfers inside the ORC unit are dictated by (i) the heat sink and the heat source supply conditions, (ii) the pump/expander rotational speeds, (iii) the ambient temperature, (iv) the components geometry and, finally, (v) the total mass of working fluid enclosed in the system. A true off-design model should account for this univocal relationship. In order to make the simulations free of such assumptions, the ORC model must implement both the energy and the mass balances in the system.
Besides the energy transfers, the model must account for the total charge of fluid in the system and simulate its repartition through the components in function of the operating conditions. Such a model is known as charge-sensitive.

Charge-sensitive models are well known for refrigeration systems for which they have been extensively used for both design and performance analyses (e.g. see [18-21]). However, their use for ORC power systems is much less common. For steady-state simulations, a thorough search of the literature yielded only two articles dedicated to ORC charge-sensitive modelling. A first paper was proposed by Ziviani et al. [16] which described an ORC model developed in Python. The model could either use a specified subcooling or account for the total charge of working fluid. A simplified method to simulate the liquid receiver was introduced. Heat transfer coefficients in the various components were calculated with state-of-the-art correlations and Zivi's void fraction model characterized the two-phase flows. The overall cycle model was validated against two experimental setups featuring different cycle architectures. When the charge of fluid was specified as input, the overall cycle efficiency was estimated within a maximum 
Table 1

Non-exhaustive list of off-design performance studies applied to ORC systems (for steady-state simulations).

\begin{tabular}{|c|c|c|c|}
\hline Authors & System description & Summary & Assumptions in the system state \\
\hline Gurgenci [4] & $\begin{array}{l}150 \mathrm{kWe} \text { ORC unit supplied by a solar pond (R114, } \\
\text { dynamic turbine, shell-and-tube HEX) }\end{array}$ & $\begin{array}{l}\text { Development of a semi-analytical model which derives } \\
\text { the system off-design performance based on the design } \\
\text { point and the identification of empirical black-box } \\
\text { parameters. The parameters must be calibrated with data } \\
\text { from an ORC system operated following a predefined } \\
\text { control strategy (control analysis cannot be investigated } \\
\text { with such model). The model does not account explicitly } \\
\text { for the components geometry. No experimental } \\
\text { validation presented }\end{array}$ & $\begin{array}{l}\text { Imposed superheating }(0 \mathrm{~K}) \text { and } \\
\text { subcooling }(0 \mathrm{~K})\end{array}$ \\
\hline
\end{tabular}

Wang et al. [5] CPC solar collectors supplying a $250 \mathrm{kWe}$ ORC unit (R245fa, multi-stage turbine, BPHEXs, thermal storage)
Semi-empirical off-design model of an ORC built by the interconnection of components submodels. The authors assumed a sliding pressure control of the ORC to keep a constant superheating and a varying cooling mass flow rate to ensure a same approach point in the condenser. No experimental validation provided
Hu et al. [6] $70 \mathrm{kWe}$ geothermal (R245fa, radial-inflow turbine, BPHEXs)
Three control schemes are investigated to operate a 70 kWe geothermal ORC unit, namely a constantpressure strategy, a sliding-pressure strategy and optimal-pressure strategy. Both the fluid mass flow rate and variable inlet guide vanes are used to adapt the power plant behaviour in function of the operating conditions (variation of the heat source supply temperature and mass flow rate)
Manente et al. [7] Theoretical 6 MWe ORC system for a geothermal application (isobutane or R134a, fictive turbine, heat exchanger and pump)
Off-design model used to find the optimal operating parameters (pump speed, turbine capacity factor and air flow rate through the condenser) that maximize the electricity production in response to changes of the ambient temperatures between 0 and $30^{\circ} \mathrm{C}$ and geofluid temperatures between 130 and $180^{\circ} \mathrm{C}$. It is an hybrid dynamic/static model i.e. it includes two capacitive elements to account for the system inertia in transient conditions
Quoilin [8] Experimental 2 kWe ORC prototype (R123, scroll expander, diaphragm pump, BPHEXs)
Semi-empirical off-design model of an ORC built by the interconnection of submodels characterizing each component. ORC model used to find best pump and expander speeds in order to maximize the sytem net thermal efficiency (just on one point)
Lecompte et al. [9] Experimental $11 \mathrm{kWe}$ ORC prototype (R245fa, BPHEXs, centrifugal pump, twin screw expander)
Off-design model developed for each system components Imposed subcooling and couplet together for simulating the entire ORC. Investigation of the optimal pump rotational speed which maximizes the system net power output. Comparing superheated and partial-evaporative operations, the latter shows an improvement of the net power output between $2 \%$ and $12 \%$ over the first

\section{Partial off-design model of an ORC unit developed to} conduct a part-load performance analysis. The study investigates the influence of the evaporating pressure, the condensing pressure, the expander speed and the expander supply temperature on the system performance. Only accounts for the expander, the pump and the recuperator off-design behaviours, no model used for the evaporator nor the condenser. Do not account of the heat source, the heat sink and the ambient conditions

net

Dickes et al. [11] Two experimental units: (i) $3 \mathrm{kWe}$ ORC system (R245fa, BPHEXs, scroll expander, diaphragm pump); (ii) $10 \mathrm{kWe}$ ORC unit (R245fa, BPHEXs, scroll expander, diaphragm pump)
Comparison of different modelling approaches (constantefficiency, polynomial-based and semi-empirical) for the off-design simulation of ORC power systems. The analysis is performed at both component- and cycle-level and the model performance are evaluated in terms of fitting and extrapolation abilities
Li et al. [12] Geothermal source supplying a theoretical 1.5 MWe Kalina (KCS34) unit $\left(\mathrm{H}_{2} \mathrm{O}+\mathrm{NH}_{3}\right.$, multi-stage axial turbine, centrifugal pump, 4 BPHEXs)
Analysis of the system performance in response to variations of the geothermal source mass flow rate, the geothermal source temperature and the heat sink temperature. Sliding pressure control strategy applied to the Kalina power plant

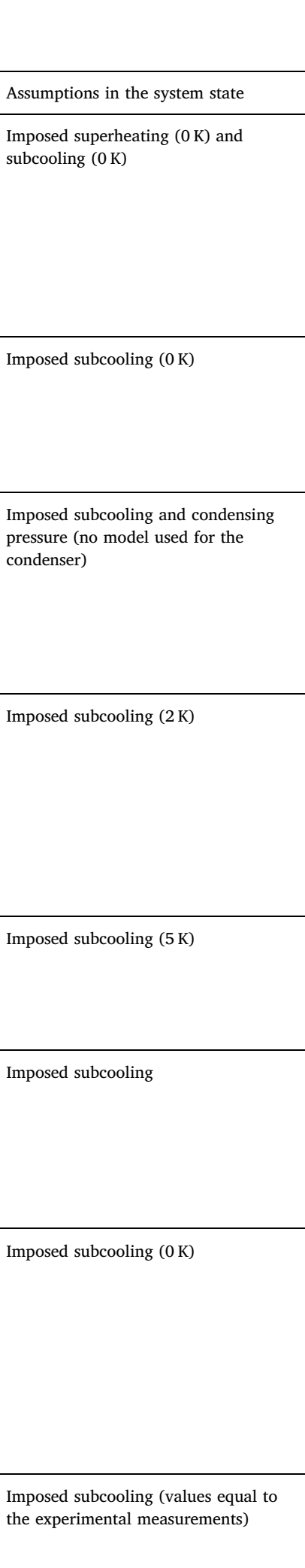

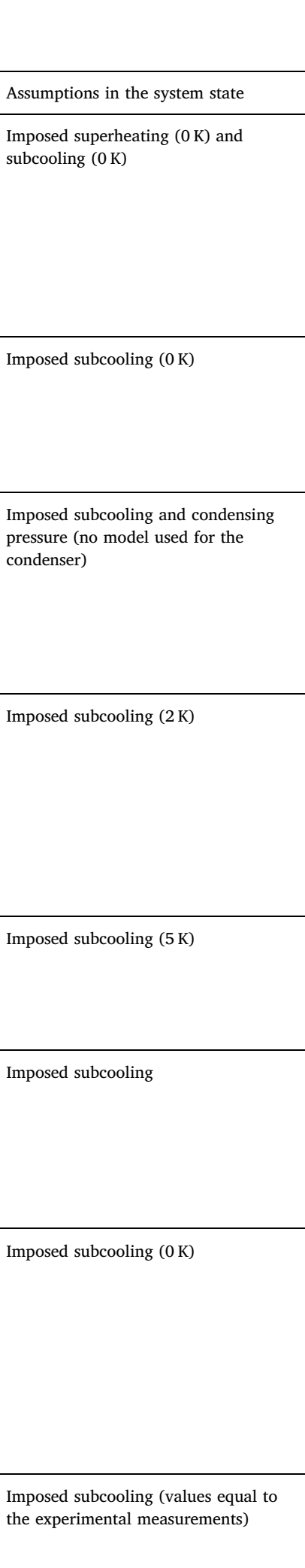

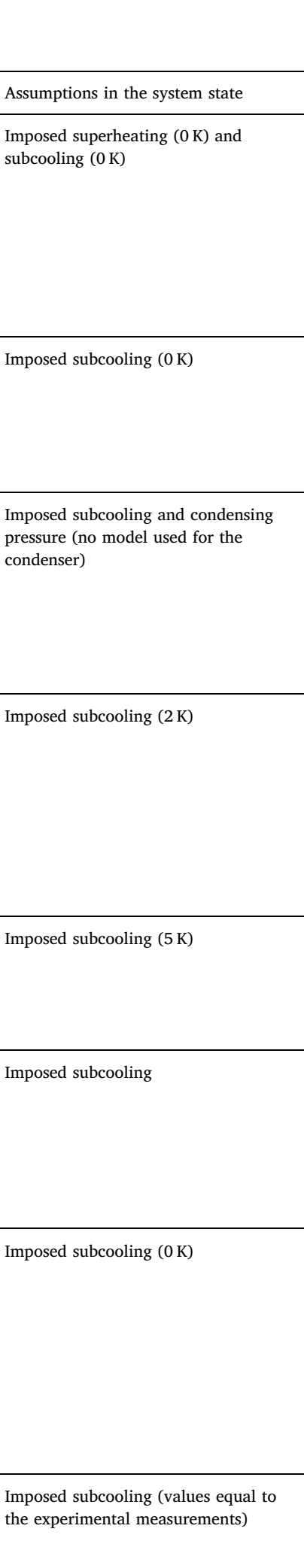

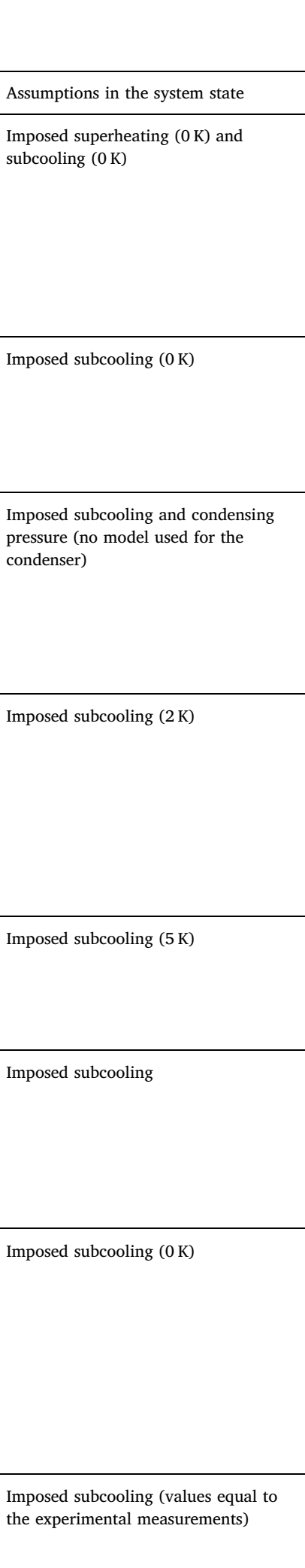

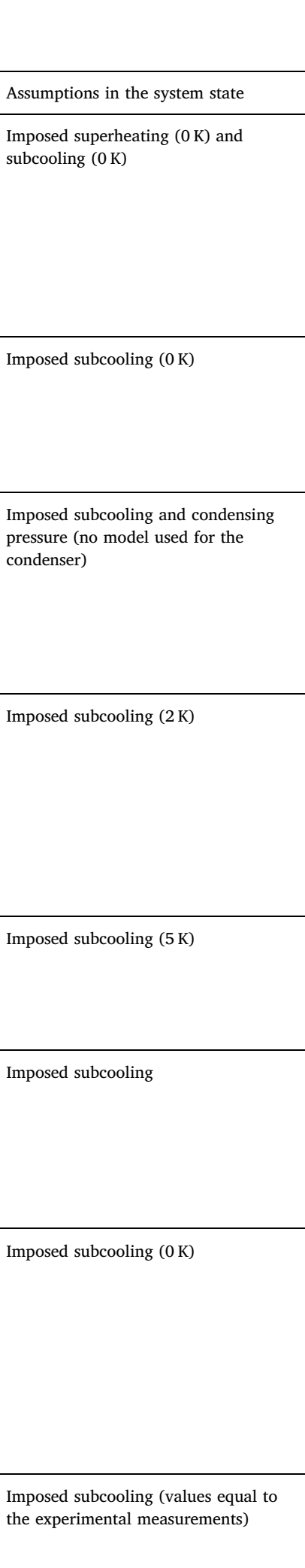

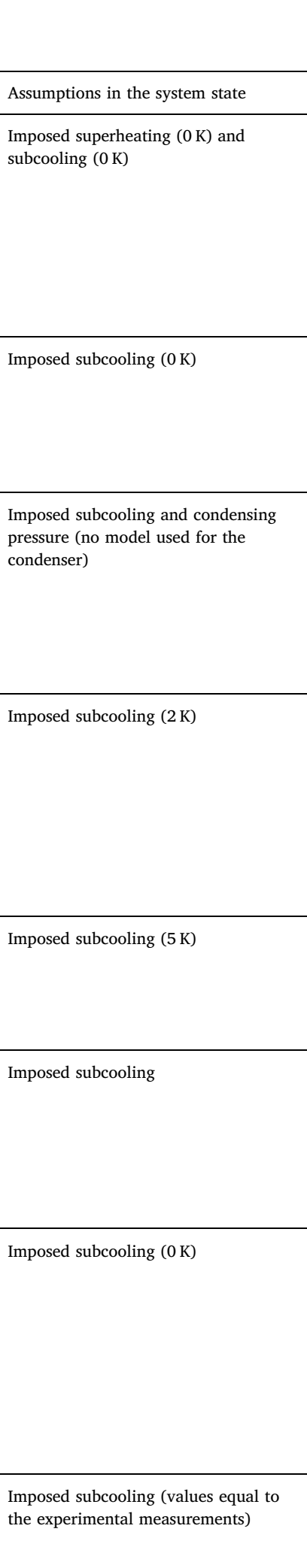

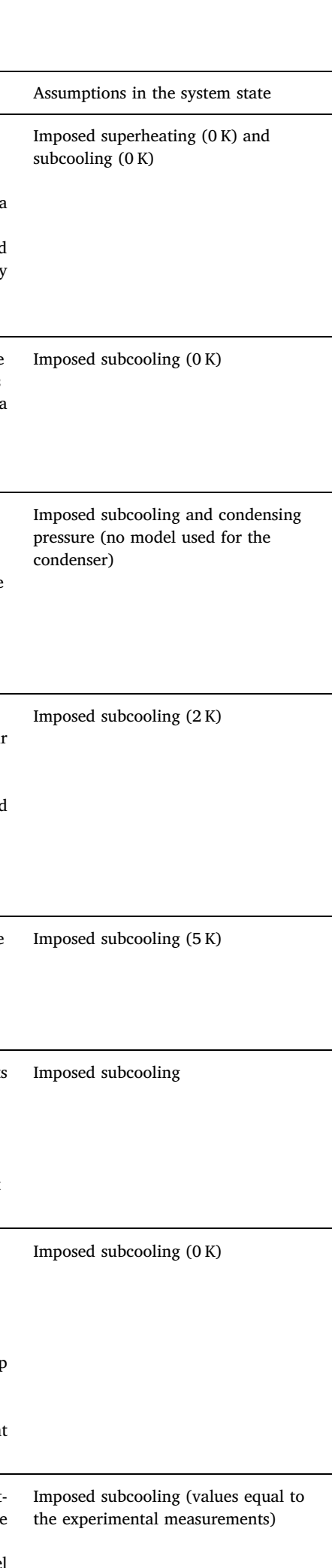

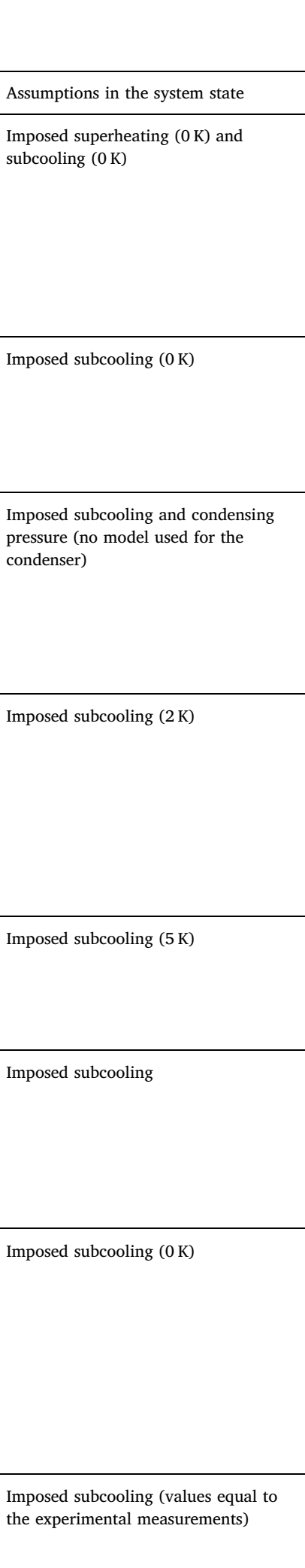

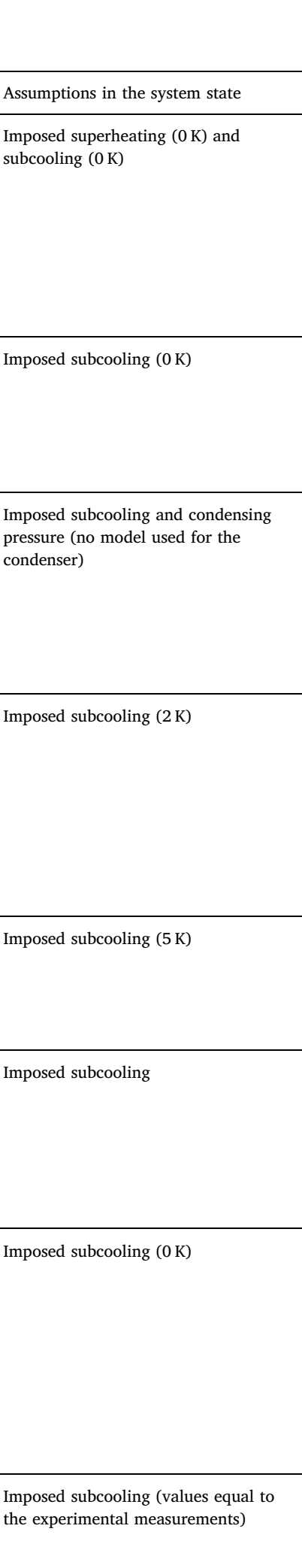

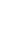

(1) 
Table 1 (continued)

\begin{tabular}{|c|c|c|c|}
\hline Authors & System description & Summary & Assumptions in the system state \\
\hline Song et al. [13] & $\begin{array}{l}\text { WHR } 530 \mathrm{kWe} \text { ORC system }(\mathrm{WF}=\mathrm{R} 123 \text {, radial } \\
\text { inflow turbine) }\end{array}$ & $\begin{array}{l}\text { After choosing the design point and the working fluid, an } \\
\text { off-design model is used to assess the influence of the } \\
\text { heat source and the cooling water supply temperatures } \\
\text { on the system performance }\end{array}$ & $\begin{array}{l}\text { Imposed subcooling (maybe more } \\
\text { assumptions, the ORC model is not } \\
\text { completely described in the paper) }\end{array}$ \\
\hline $\begin{array}{l}\text { Möller and } \\
\text { Gullapalli. } \\
{[14,15]}\end{array}$ & $\begin{array}{l}\text { Two CraftEngine CE10 (R245fa and R134a as WF, } \\
\text { scroll expanders, BPHEXs) }\end{array}$ & $\begin{array}{l}\text { Development of the "SSP ORC simulation" tool based on } \\
\text { the SWEP SPP software. The software includes a detailed } \\
\text { modelling of the BPHEXs and is aimed for both design } \\
\text { and off-design performance modelling. Model validation } \\
\text { with two case study }\end{array}$ & $\begin{array}{l}\text { The ORC model structure is not well } \\
\text { documented but it is not a charge- } \\
\text { sensitive model }\end{array}$ \\
\hline Ziviani et al. [16] & $\begin{array}{l}\text { Two experimental systems: (i) } 11 \mathrm{kWe} \text { ORC unit } \\
\text { (R245fa, BPHEXs, screw expander, centrifugal } \\
\text { pump); (ii) } 5 \mathrm{kWe} \text { ORC unit (R134a, BPHEXs, scroll } \\
\text { expander, diaphragm pump) }\end{array}$ & $\begin{array}{l}\text { Development and validation of an ORC model which is } \\
\text { either charge-sensitive or subcooling-sensitive. The ORC } \\
\text { model and the subcomponent models are validated with } \\
\text { experimental measurements. It is the first paper related } \\
\text { to charge-sensitive ORC modelling known by the authors }\end{array}$ & $\begin{array}{l}\text { None if the model is charge-sensitive, } \\
\text { otherwise the subcooling is imposed }\end{array}$ \\
\hline Liu et al. [17] & $\begin{array}{l}\text { Theoretical } 3 \mathrm{kWe} \text { WHR ORC system }(\mathrm{WF}=\mathrm{R} 123 \text {, } \\
\text { scroll expander, shell-and-tube condenser, fin-tube } \\
\text { evaporator, no recuperator) }\end{array}$ & $\begin{array}{l}\text { Development of a charge-sensitive model used to (i) } \\
\text { compute the charge of WF in nominal conditions; (ii) } \\
\text { study the heat exchangers behaviour in part-load } \\
\text { conditions; (iii) assess the impact of different charge in } \\
\text { part-load conditions. It is the second paper related to } \\
\text { charge-sensitive ORC modelling known by the authors }\end{array}$ & None, it is a charge-sensitive model \\
\hline
\end{tabular}

relative error of $\pm 20 \%$ and the accuracy on the subcooling predictions was within $\pm 1.5 \mathrm{~K}$. Liu et al. [17] proposed another mass-oriented model to simulate a $3 \mathrm{kWe}$ WHR unit. Their model implemented stateof-the-art correlations to evaluate the heat transfer coefficients and the Lockhard-Martinelli void fraction model to characterize two-phase flows. The off-design model was used to compute the charge of WF required in nominal conditions, to study the heat exchangers behaviour in part-load conditions and to assess the impact of different charges in the ORC system. The study was only theoretical and no experimental validation was provided. Regarding dynamic ORC models, taking the charge into account is more common. Both finite-volume and movingboundary methods have been developed in order to simulate the heat exchangers. Most existing works rely on a simple homogeneous void fraction model to characterize the two-phase flows. Extensive details on this topic can be found in the dedicated literature [22-25].

This paper is also about the charge-sensitive modelling of ORC power systems. The purpose of the present work is to provide a reliable tool for predicting the steady-state performance of ORC engines in any off-design condition. The model is aimed to retrieve the system performance based on its boundary conditions only (i.e. without assumption regarding the system state). To this end, off-design models are developed to simulate each component of the ORC and then assembled to simulate the entire system. A particular focus is given to the modelling of the heat exchangers and the liquid receiver. A $2 \mathrm{kWe}$ ORC unit is chosen as case study and experimental data are used as reference for the models calibration and validation. Although this work uses a labscale unit as case study, the methodology proposed here can be applied to any other system architecture. In comparison to the existing publications, the present work offers an original contribution in the following aspects:

- The paper highlights the importance and the complexity to properly identify the convective heat transfer coefficients in multi-zone heat exchangers. It is shown how state-of-the-art correlations can be used as initial guesses and three different identification methods are compared. Ultimately, this article shows how the charge of working fluid can be used to better identify these coefficients and thus to improve the reliability of the off-design ORC model.

- The impact of the void fraction assumptions is assessed by comparing five different models from the scientific literature.

- The modelling of the liquid receiver is discussed in detail. The paper highlights the numerical issues arising when such a liquid receiver is present in the ORC system. To ensure high robustness, a dedicated solver is presented to simulate the entire ORC system.

The paper is structured as follows: firstly, the test rig used as reference is described in Section 2. Then, in Section 3, the heat exchangers modelling is analysed in detail. Section 4 is dedicated to the modelling of the other components (i.e. the pump, the expander, the liquid receiver and the piping) while the simulation of the entire ORC power system is presented in Section 5. Finally, in Section 6, the ORC model is validated by comparison to the experimental data and the results are discussed. For the sake of conciseness, most of the models equations are given in Appendix A. The modelling environment used to conduct this study is Matlab ${ }^{\circledR}$ and thermo-physical properties of the fluids are retrieved using CoolProp [26]. All the models developed in the frame of this work may be found in the open-access library ORCmKit [27].

\section{Case study and reference dataset}

The system considered here is the Sun2Power ORC unit built by the University of Liège [28]. It is a $2 \mathrm{kWe}$ recuperative ORC system using HFC-245fa (1,1,1,3,3-Pentafluoropropane) and developed for a solar thermal application [29]. Although the ORC unit is aimed to operate with parabolic trough collectors, the experimental measurements presented in this work are gathered using an electrical boiler as heat source. As depicted in Figs. 1 and 2, the ORC system is composed of a variable-speed scroll expander, a diaphragm pump, a liquid receiver and three heat exchangers. Both the evaporator and the recuperator are thermally-insulated brazed plate heat exchangers (BPHEXs) while an air-cooled fin coil heat exchanger (FCHEX) is used for the condenser. Such a system architecture is very common in micro- to medium-scale power applications and numerous similar ORC units have been built for both research (e.g. [30-32]) and commercial purposes (e.g. [33-36]). Here, the system features three control variables: the pump, the fan condenser and the expander rotational speeds. The test rig is also fully instrumented with flow meters, thermocouples, pressure sensors and power meters in order to properly record the performance of the global system and of each subcomponent individually. Although it would have been interesting for this work to measure the working fluid mass repartition through the system, the test rig does not feature individual scales to weigh each component. However, the total charge (mass) of working fluid enclosed in the system is known to be $26 \mathrm{~kg}( \pm 0.5 \mathrm{~kg})$. 


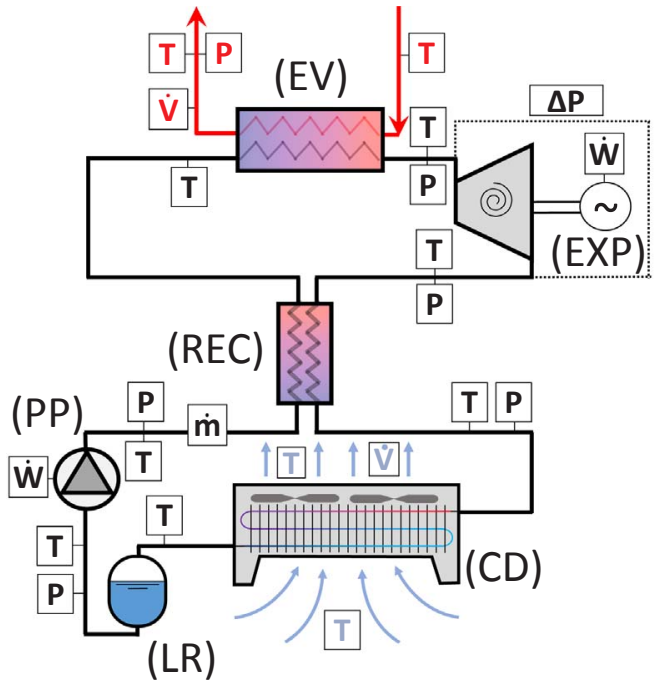

$\mathbf{P}$ : pressure sensor - $\mathbf{T}$ : thermocouple $-\dot{\mathbf{m}}$ : mass flow meter $\dot{\mathbf{W}}$ : power meter $-\dot{\mathbf{V}}$ : volumetric flow meter

Fig. 1. Layout of the $2 \mathrm{kWe}$ Sun2Power ORC system.

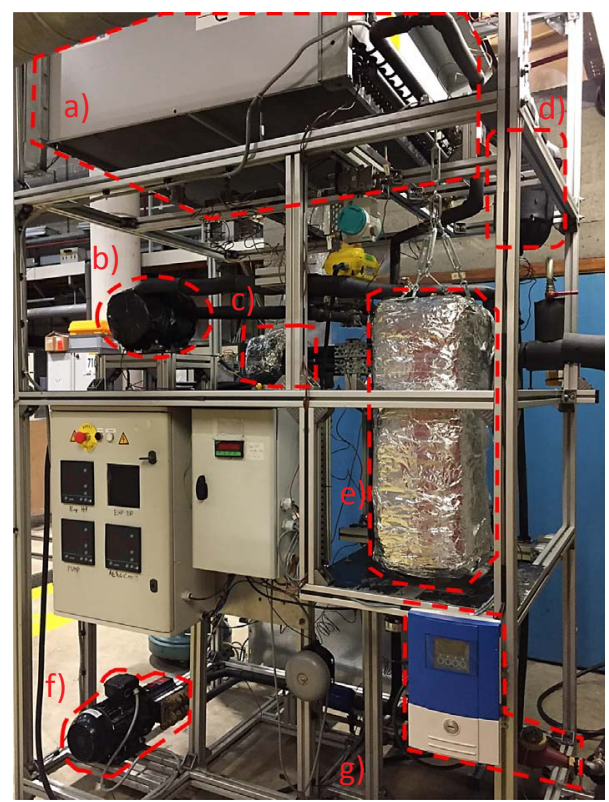

Fig. 2. Photo of the test rig. (a) Condenser (b) Expander (c) Recuperator (d) Liquid receiver (e) Evaporator (f) Pump (g) HTF flow meters.

The influence of the lubricating oil dissolved in the working fluid is neglected because of its small volume concentration ( $<5 \%$ liquid vol.). A summary of the system features is proposed in Table 2 .

Using this test rig, an experimental campaign is conducted and 40 steady-state points are gathered as reference dataset. During the experimental campaign, the ORC system is not operated in accordance with any dedicated control strategy. Instead, the test rig is driven over an extended range of conditions (including non-optimal points) in order to properly characterize the system in off-design and part-load operation. The reference steady-state points are obtained by averaging the experimental measurements over 5-min periods in stabilized regimes (i.e. conditions for which the deviations in all the temperatures are lower than $1 \mathrm{~K}$, with constant mass flow rates and with non-sliding pressures) and by the application of a data post-treatment. This posttreatment automatically identifies measurement outliers and applies a reconciliation method to account for the sensors inaccuracy. The reference dataset and the reconciliation method are extensively described in [11]. The ranges of the operating conditions covered by the dataset are given in Table 3. These experimental points will be used as reference for the study presented in this work.

\section{Heat exchangers modelling}

To conduct off-design simulations, a reliable modelling of the heat exchangers is of utmost importance. Unlike in steam power plants or higher-capacity systems, small-scale ORC units often use a single oncethrough heat exchanger to perform the complete heating (resp. cooling) of the working fluid. Considering that the fluid experiences a phasechange in both the evaporator and the condenser, several states of fluid (i.e. liquid, two-phase and/or vapour phases) often coexist in a same component. Therefore, a single heat exchanger can be divided in $(N)$ multiple zones. To account for this division, a moving-boundary model is chosen to simulate the heat exchangers. In such approach, each zone is characterized by a global heat transfer coefficient $U_{i}$ and a surface area $A_{i}$ through which a given rate of heat $\dot{Q}_{i}$ is transferred (Eqs. (A.1) and (A.2)). Based on the supply conditions only, the effective heat $\dot{Q}_{H E X}$ transferred between the hot and the cold fluids is calculated such as the total surface area occupied by the different zones corresponds to the geometrical surface area of the component $A_{H E X}$ (Eqs. (A.3) and (A.4)). To this end, the generalized and robust moving-boundary algorithm proposed by Bell et al. [37] is employed.

Regarding the charge modelling, the mass of working fluid enclosed in a heat exchanger of volume $V_{H E X}$ can be computed as the sum of the masses included in each of the $\mathrm{N}$ sub-zones, i.e.

$M_{H E X}=\sum_{i=1}^{N} \overline{\rho_{i}}\left(\omega_{i} V_{H E X}\right)$

where $\omega_{i}$ is the volume fraction occupied by the $i$ th zone in the heat exchanger (Eq. (A.5)) and $\overline{\rho_{i}}$ is the corresponding mean density of the fluid. Based on Eq. (1), it appears that a reliable charge-sensitive HEX model implies two conditions:

1. A proper knowledge of $\omega_{i}$, i.e. the spatial fraction occupied by each zone of fluid in the heat exchanger. As shown through Eqs. (A.1)-(A.3), this spatial division is affected by the convective heat transfer coefficients used to simulate the two media.

2. A proper evaluation of the fluid density along the heat exchanger. In the case of single-phase zones, the density calculation is straightforward and can be determined from the fluid thermodynamic state. In the case of a two-phase flowing mixture, the density is not only function of the fluid pressure, temperature and quality, but also depends on the void fraction characterizing the flow. Therefore, the charge calculation in the HEX is directly impacted by the void fraction model used to characterize the boiling or condensing processes.

The following subsections investigate in details the impact of the convective heat transfer coefficients and the void fractions assumptions

Table 2

Main features of the two experimental facilities.

\begin{tabular}{lll}
\hline Component & Name/Model/Brand & Comment \\
\hline Working fluid & R245fa & n.a. \\
Heat source fluid & Pirobloc HTF-Basic & Thermal oil \\
Heat sink fluid & Ambient air & n.a. \\
Scoll expander & $V_{\text {swept }}=12.79 \mathrm{~cm}^{3}, r v_{\text {in }}=2.19$ & variable speed \\
Diaphragm pump & Hydracell G03 & variable speed \\
Condenser & FCHEX Alfa Laval Solar Junior 121 & fan with variable speed \\
Evaporator & BPHEX Alfa Laval CB76-100E & thermally-insulated \\
Recuperator & BPHEX Alfa Laval CB30-40H-F & thermally-insulated \\
Liquid receiver & Vertical tank & $V_{L R}=5.7 l$ \\
\hline
\end{tabular}


Table 3

Operating ranges of the reference dataset.

\begin{tabular}{llll}
\hline Variable & Min. & Max. & Unit \\
\hline$\dot{m}_{h t f, h}$ & 910 & 990 & {$[\mathrm{~g} / \mathrm{s}]$} \\
$T_{h t f, s u, h}$ & 88 & 120 & {$\left[{ }^{\circ} \mathrm{C}\right]$} \\
$\dot{Q}_{e v}$ & 3.4 & 15 & $\mathrm{~kW}$ \\
$\dot{m}_{h t f, c}$ & 0.15 & 1.45 & {$[\mathrm{~kg} / \mathrm{s}]$} \\
$T_{h t, s u, c}$ & 17 & 25 & {$\left[{ }^{\circ} \mathrm{C}\right]$} \\
$\dot{Q}_{c d}$ & 2.9 & 13.3 & $\mathrm{~kW}$ \\
$\dot{m}_{w f}$ & 16 & 70 & {$[\mathrm{~g} / \mathrm{s}]$} \\
$P_{e v}$ & 6.5 & 14.5 & {$[\mathrm{bar} \mathrm{abs}]$.} \\
$P_{c d}$ & 1.6 & 6.6 & {$[\mathrm{bar} \mathrm{abs}]$.} \\
$\dot{W}_{n e t}$ & 23 & 1170 & {$[\mathrm{~W}]$} \\
$\dot{Q}_{\text {rec }}$ & 0.13 & 3.3 & {$[\mathrm{~kW}]$} \\
$\eta_{\text {net }, \text { ORC }}$ & 0.5 & 8 & {$[\%]$} \\
$M_{w f, t o t}$ & $26( \pm 0.5)$ & $26( \pm 0.5)$ & {$[\mathrm{kg}]$} \\
\hline
\end{tabular}

used to model the heat exchangers. The reliability of the models is evaluated by confronting the simulations results to the experimental measurements, both in terms of thermal performance and charge inventory predictions. At this stage of the study, the analysis is performed by considering each heat exchanger individually from each other, the modelling of the entire closed-loop system is presented latter in the text (cfr. Section 5).

\subsection{Influence of the convective heat transfer coefficients}

As presented in Section 2, the ORC system features two types of heat exchangers, namely an air-cooled fin coil condenser and two brazed plate heat exchangers (BPHEXs). For these three heat exchangers, the identification of the heat transfer coefficients from the experimental measurements is not straightforward. Since several zones coexist in a single component, very different values of convective heat transfer coefficients can predict identical thermal performance (see Fig. 3 for an example). Unless the reference dataset includes single-zone conditions (i.e. operating conditions with only a liquid-phase, a vapour-phase or a two-phase flow in the HEXs), the identification of these convective coefficients based on heat transfer measurements only is risky because the size of the different zones is a priori unknown. Alternatively, it is possible to use state-of-the-art correlations to calculate the convective heat transfer coefficients. For both technologies, many different correlations may be found in the scientific literature. These correlations generally evaluate the Nusselt number $(\mathrm{Nu}=H \cdot L / k)$ as a function of the flow conditions, the fluid properties and some geometrical parameters of the heat exchanger. In most cases, these correlations are purely empirical and calibrated to fit some experimental data. Because there is not one unique reference correlation for each type of heat exchanger, several candidates (among the most common employed nowadays) are tested to model both technologies. More specifically, nine different correlations are investigated to simulate the brazed plate heat exchangers, i.e.:

- three correlations for single-phase flows in both the recuperator and the evaporator, i.e. the correlations proposed by Martin [38], Wanniarachchi et al. [39] and Thonon [40]. It must be noted that the same single-phase correlation is applied for both the hot and cold fluid in a same heat exchanger;

- three correlations for the boiling flow in the evaporator, i.e. the correlations proposed by Amalfi et al. [41], Han et al. [42] and Cooper [43];

- three correlations for the condensing flow in the recuperator, namely the correlations proposed by Longo et al. [44], Han et al. [45] and Shah [46].

Regarding the air-cooled condenser, the following correlations are evaluated:

- the common correlation proposed by Gnielinski [47] for singlephase flows in the horizontal tubes;

- the general correlation proposed by Cavallini et al. [48] for condensing flows in the condenser tubes;

- two correlations for the air flow across the coil, i.e. the empirical laws proposed in [47] and the one proposed by Wang et al. [49]

Fewer correlations are tested for the condenser because of the better characterized flow occurring in the horizontal tubes. For the sake of conciseness, the equations constituting these heat transfer correlations are not presented here, but they can be found in Appendix B. Because of the multiple zones coexisting in the heat exchangers, different correlations must be coupled to simulate one component. As listed in Table 4, it results nine different models for the brazed plate heat exchangers (i.e. the evaporator and the recuperator), and two models for the condenser. In order to assess their reliability, the different models presented in Table 4 are evaluated in the exact same conditions as in the reference dataset and the heat transfer predicted by each model is confronted to the experimental observations.

In the case of the condenser, the two models investigated (i.e. the models $C D_{A}$ and $C D_{B}$ ) demonstrate fairly good agreement with the experimental data. As shown in Fig. 4, both models properly predict the heat transfer and the modelling deviations are smaller than $10 \%$ (on average, the relative errors are $2.6 \%$ and $1.9 \%$ for the models $C D_{A}$ and $C D_{B}$ respectively). Regarding the brazed plate heat exchangers, the modelling performance of the different correlations is significantly lower. For both the recuperator and the evaporator, it appears that all the models, in every case, highly overpredict the convective heat transfer coefficients in the BPHEXs. In the case of the recuperator, as depicted in Fig. 5, the simulated heat transfers are on average overpredicted by $40 \%$ in comparison to the experimental data. Regarding the evaporator, the heat powers predicted by the models match
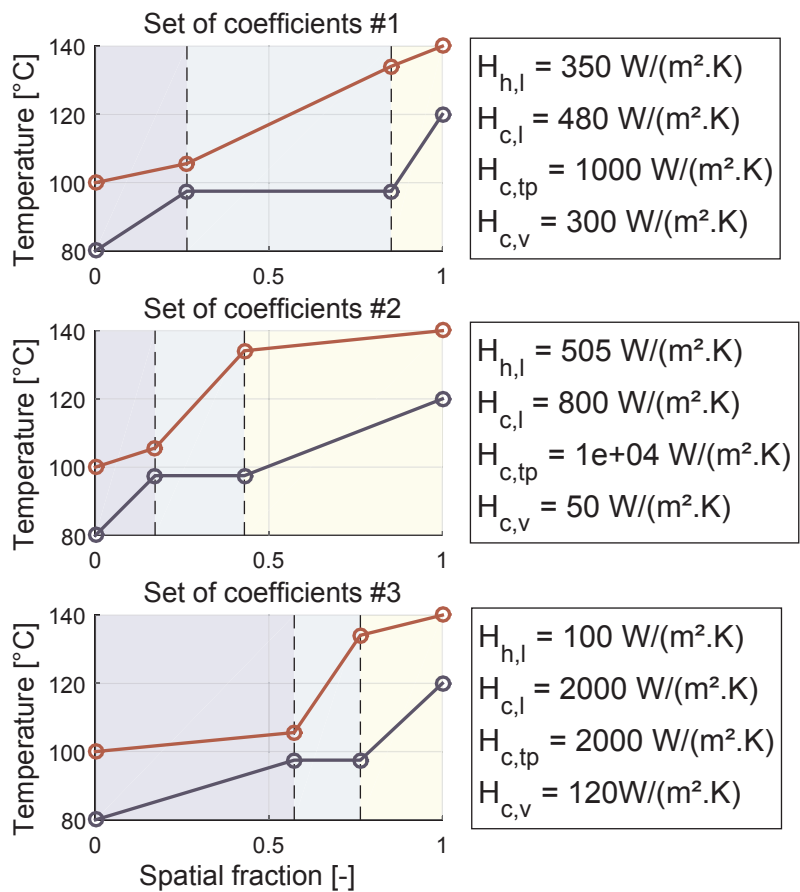

Fig. 3. Thermal transfer in an evaporator with three different set of convective heat transfer coefficients (temperature profile vs. normalized length). The red and the blue lines correspond to the temperature profiles of the hot and the cold fluids, respectively. The thermal performance are identical (same heat transfers) but the spatial distribution of the different zones is totally different. (For interpretation of the references to color in this figure legend, the reader is referred to the web version of this article.) 
Table 4

Heat exchangers models investigated for the evaporator, the recuperator and the condenser (NB: ${ }^{(1)}=$ Han's boiling correlation [42]; ${ }^{(2)}=$ Han's condensation correlation [45]).

Evaporator models

(correlations for single-phase \& boiling flows in a BPHEX)

\begin{tabular}{|c|c|c|c|c|c|}
\hline$E V_{A}:$ & Martin + Amalfi & $E V_{D}:$ & Martin + $\operatorname{Han}^{(1)}$ & $E V_{G}:$ & Martin + Cooper \\
\hline$E V_{B}:$ & Wanniarachchi + Amalfi & $E V_{E}:$ & Wanniarachchi $+\operatorname{Han}^{(1)}$ & $E V_{H}:$ & Wanniarachchi + Cooper \\
\hline$E V_{C}:$ & Thonon + Amalfi & $E V_{F}:$ & Thonon $+\operatorname{Han}^{(1)}$ & $E V_{I}$ : & Thonon + Cooper \\
\hline
\end{tabular}

Recuperator models

(correlations for single-phase \& condensing flows in a BPHEX)

\begin{tabular}{|c|c|c|c|c|c|}
\hline$R E C_{A}:$ & Martin + Longo & $R E C_{D}:$ & Martin $+\operatorname{Han}^{(2)}$ & $R E C_{G}:$ & Martin + Shah \\
\hline$R E C_{B}$ & Wanniarachchi + Longo & $R E C_{E}:$ & Wanniarachchi $+\operatorname{Han}^{(2)}$ & $R E C_{H}:$ & Wanniarachchi + Shah \\
\hline$R E C_{C}:$ & Thonon + Longo & $R E C_{F}:$ & Thonon $+\operatorname{Han}^{(2)}$ & $R E C_{I}$ : & Thonon + Shah \\
\hline
\end{tabular}

Condenser models

(correlations for single-phase \& condensing flows in tubes + air flow through the coil)

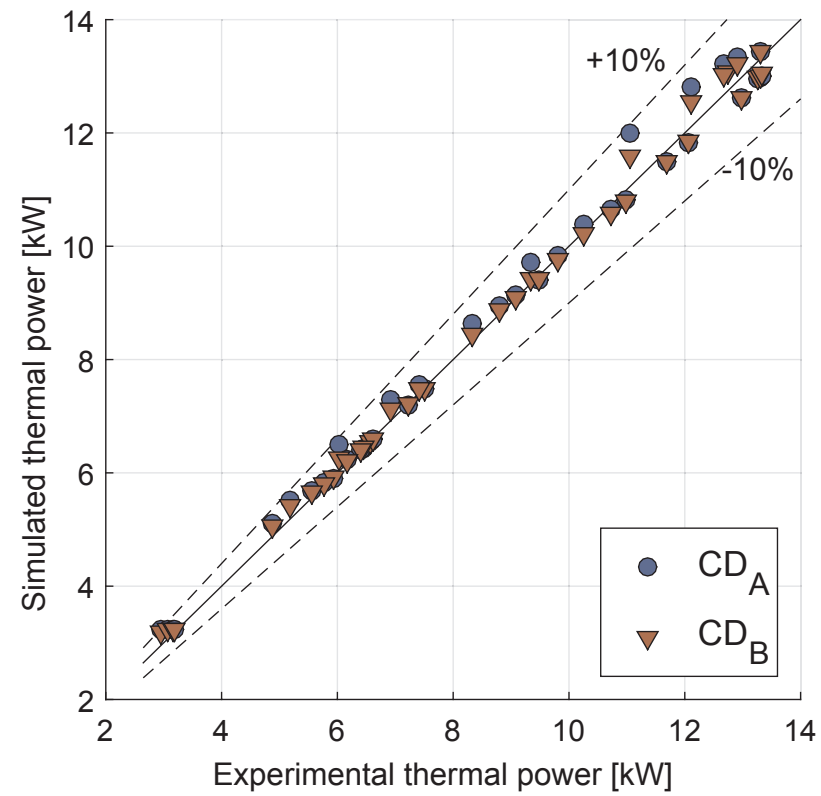

Fig. 4. Parity plot of the condenser heat transfer (simulation results vs. experimental data).

relatively well the experimental measurements. Indeed, the heat exchanger being slightly oversized for the tests conducted, a small pinch point is recorded experimentally for most of the points (i.e. lower than $3 \mathrm{~K}$ ) while all the models predict a maximal heat transfer (i.e. with a pinch point equal to zero) whatever the operating conditions. However, the surface areas calculated for such zero-pinch heat transfers are much smaller than the effective size of the evaporator. Therefore, the convective heat transfer coefficients provided by the state-of-the-art correlations are also largely overestimated in the evaporator. Other studies (e.g. $[50,51]$ ) demonstrated similar results.

These poor predictions from the state-of-the-art correlations may be explained by different reasons. Firstly, the single-phase correlations are all empirically determined using water as heat transfer fluid and their extrapolability to organic fluids is not verified. Secondly, even though the two-phase correlations are developed with refrigerants (or other organic fluids), the operating conditions used to calibrate them are more typical of refrigeration systems than those encountered in ORC units. In the case of condensing flows, the saturation temperatures in the two technologies (ORC and HVAC) are of the same order $\left(20^{\circ} \mathrm{C}\right.$ to more than $50^{\circ} \mathrm{C}$ ). However, the evaporating temperature in HVAC systems is much smaller than in ORC power units $\left(-10^{\circ} \mathrm{C} / 20^{\circ} \mathrm{C}\right.$ vs.

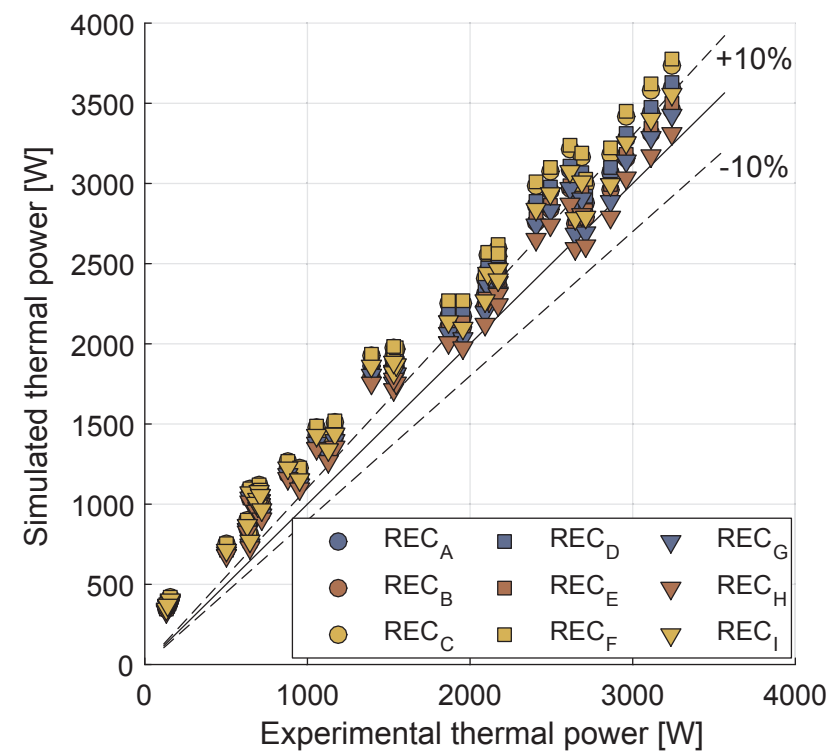

Fig. 5. Parity plot of the recuperator heat transfer (simulation results vs. experimental data).

$\left.80^{\circ} \mathrm{C} / 150^{\circ} \mathrm{C}\right)$. Therefore, the validity of the correlations to characterize boiling flows in ORC systems is not guaranteed. Finally, the correlations require a good knowledge of the BPHEX geometry (i.e. the chevron angle, the plate thickness, the enlargement factor, the corrugation pattern, etc.). Although some characteristics may be retrieved indirectly from the heat exchanger datasheet, uncertainties remain and these errors may alter the proper predictions of the correlations.

From these results, it appears that the correlations evaluated in this work (especially for the BPHEXs) cannot not be used directly to simulate the investigated ORC system. However, the form of their equations is a good guess to compute the convective heat transfer coefficients. As a compromise, it is proposed to re-identify the empirical parameters of these correlations so as to better fit the experimental measurements. To this end, three different identification methods, each giving an additional degree of freedom, are applied for all the models given in Table 4, i.e.:

- Method \#1: only the most influential correlation in the heat exchanger (i.e. the one referring to the highest thermal resistivity) is scaled by means of a single factor $c$, i.e.

$N u_{\text {new }}=c \cdot N u$ 
- Method \#2: idem as method \#1, except that all the correlations used to simulate the heat exchanger are scaled with independent factors $c_{j}$, i.e.

$N u_{n e w, j}=c_{j} \cdot N u_{j}$

Therefore, two (resp. three) scaling factors are tuned for each BPHEX (resp. FCHEX) model.

- Method \#3: idem as method \#2, except that, additionally, the empirical exponents on the Reynolds number ( $m$ in Eq. (4)) are also tuned by factors $c_{k}$, i.e.

$N u_{n e w, j k}=c_{j} \cdot N u_{j}\left(R e^{c_{k} \cdot m}\right)$

In total, four (resp. six) factors are tuned for each BPHEX (resp. condenser) model.

For each model listed in Table 4, the scaling factors $c_{j k}$ are tuned by minimizing the residuals between the model predictions and the experimental data. More specifically, the following objective function $\mathrm{F}$ is minimized by means of an interior-point algorithm [52], i.e.

$\min _{c_{j k}} F=\beta \cdot N R M S E+(1-\beta) \cdot \sum_{j=1}^{M} \frac{1-c_{j k}}{M}$

where the first term is referring to the Normalized Root Mean Square Error (as defined in Eq. (6)), the second term accounts for the correction applied to the correlations (aimed to be minimized as well) and $\beta$ is a weighting factor (set to 0.95 in this work).

$N R M S E=\frac{1}{\dot{Q}_{\max }-\dot{Q}_{\min }} \sqrt{\frac{\sum_{i=1}^{N}\left(\dot{Q}_{\text {exp },}-\dot{Q}_{\text {sim }, i}\right)^{2}}{N}}$

In order to compare these methods, averaged values of the NRMSE related to each modelling approach are given in Fig. 6. As expected, the larger the tuning applied to the correlations, the better the fitting of the experimental data. From these results, the method \#3 (i.e. the method changing the most the initial correlations) seems to be the best approach to evaluate the heat transfer coefficient. However, as demonstrated in the next subsection, the thermal prediction of the heat exchanger models should not be used as only indicator to assess the models validity.

\subsection{Influence of the void fraction}

As already shown in Eq. (1), the mass of working fluid enclosed in a heat exchanger can be computed as the sum of the masses included in each of the sub-zone. In the case of a single-phase zone (either subcooled or superheated), the density of the fluid is totally defined by its thermodynamic state and the enclosed mass can be easily computed as

$M_{s p}=V_{s p} \cdot \bar{\rho}_{s p}$

where $V_{s p}$ is the zone volume and $\bar{\rho}_{s p}$ is a mean value of the single-phase fluid density. In the case of a two-phase mixture, the density is not only function of the fluid thermodynamic state (i.e. its pressure, temperature and quality), but it also depends on the flow pattern characterizing the liquid and the vapour phases. To account for this effect, the two-phase flowing mixture is characterized by a void fraction $\alpha$ related to the fluid quality $x$, i.e.

$\alpha(x)=\frac{A_{c s, v}}{A_{c s}}=\frac{1}{1+\frac{1-x}{x}\left(\frac{\rho_{v}}{\rho_{l}}\right) S}$

where $A_{c s, v}$ and $A_{c s}$ are respectively the vapour flow and the total flow cross-sectional areas, $\rho_{v}$ and $\rho_{l}$ are the saturated vapour and saturated liquid densities, and $S$ is the slip (velocity) ratio between the vapour phase and the liquid phase (i.e. $S=u_{v} / u_{l}$ ). Based on the void fraction $\alpha$, the mass $M_{t p}$ enclosed in a two-phase zone of length $L$ and of cross section area $A_{c}$ can be calculated i.e.

$M_{t p}=M_{v}+M_{l}=A_{c}\left(\rho_{v} \int_{0}^{L} \alpha(x) d l+\rho_{l} \int_{0}^{L}[1-\alpha(x)] d l\right)$

It is important to note that the void fraction in Eq. (9) is integrated along $l$, i.e. the length of the zone, while $\alpha$ is expressed in terms of the fluid quality. To facilitate the calculation, a common approach is to assume a uniform heat flux in the two-phase zone [53] and thereby a linear evolution of the fluid quality along the length $l$. In this work, such an assumption is avoided and the effective spatial evolution of the quality in the heat exchanger is taken into account. To this end, the two-phase region is not evaluated as a single zone but it is further discretized into ten sub-cells. This approach is more computationally intensive, but it gains in modelling accuracy.

As for the heat transfer coefficients, many correlations may be found in the scientific literature to characterize the void fraction in function of the flow operating conditions [54]. In this work, five of the most commonly used void fraction models are considered, namely:

- the homogenous model, which assumes a slip-ratio $S$ equal to 1 ;

- the model proposed by Zivi [55], which computes the slip-ratio accounting for the operating pressure such as $S=\left(\rho_{v} / \rho_{l}\right)^{-1 / 3}$;

- the model proposed by Lockhart-Martinelli [56], which calculates $\alpha$ as an empirical function of the eponymous parameter $X_{t t}$;

- the empirical model proposed by Premoli [57] which accounts for the mass flux in the void fraction calculation;

- a second empirical mass-flux-dependent model proposed by Hughmark [58].

As a figure of comparison, the influence of these void fraction models on the density calculation is depicted in Fig. 7. The constitutive equations of these models can be found in Appendix B.

In order to compare the five void fraction models, the mass of fluid enclosed in the three heat exchangers is computed for the 40 points constituting the reference dataset. Since there is no measurement of the individual charge in each heat exchanger, the reliability of the void fraction models is assessed by comparing the total charge prediction in the entire system to the effective mass of fluid enclosed in the ORC test rig $(26 \mathrm{~kg} \pm 0.5 \mathrm{~kg})$. The total mass of fluid in the ORC is simply computed as the sum of the masses enclosed in the different components i.e.

$M_{w f, t o t}=M_{e v}+M_{r e c}+M_{c d}+M_{L R}+M_{e x p}+M_{p p}+\sum_{i} M_{p i p e, i}$

where the masses in the expander $M_{\text {exp }}$, the pump $M_{p p}$, the liquid receiver $M_{L R}$ and the various pipings $M_{\text {pipe }}$ are computed using Eqs. (A.6), (14) and (A.9). In order to numerically quantify the goodness of the charge predictions, both the mass mean value (i.e. the average mass computed over the 40 experimental points) and the mass standard deviation (to illustrate the mass scattering) are computed for the different modelling approaches. Because there are 2 models of the condenser, 9 models for the BPHEXs and 4 tuning methods, all independent from each other, 72 different combinations of the HEXs models are tested to

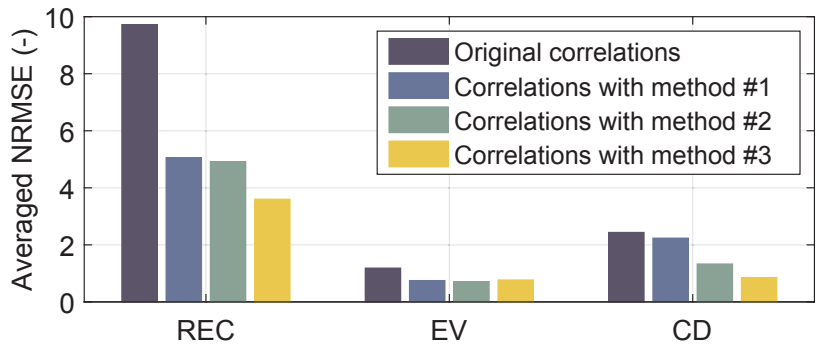

Fig. 6. Averaged values of the NRMSEs committed for each heat exchanger in function of the tuning method applied to the correlations. 


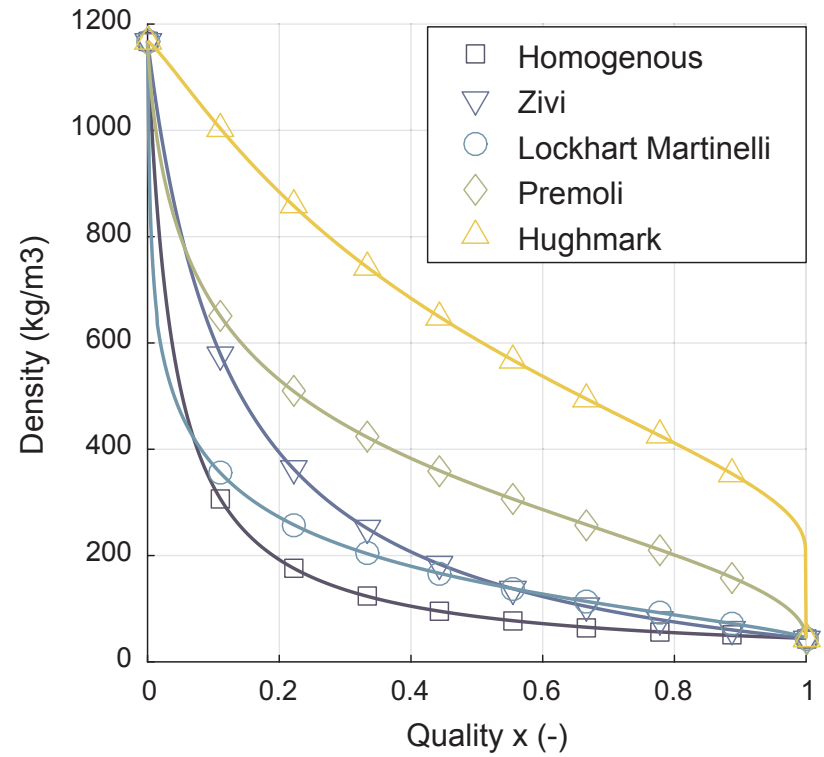

Fig. 7. Density of R245fa as a function of the quality computed with 5 different void fraction models (example conditions: $P=8 \mathrm{bar}, D_{h}=3.2 \mathrm{~mm}, G=2.97 \mathrm{~kg} \cdot \mathrm{s}^{-1} \cdot \mathrm{m}^{2}$ ).

simulate the ORC system (i.e. all the combinations possible are evaluated). For each of these 72 model combinations, the five void fractions are used to compute the total mass of working fluid enclosed in the system. Ultimately, 360 charge-sensitive simulations are performed and all the detailed results can be found in Appendix C. For the sake of clarity, averaged values of the charge inventory are depicted in Fig. 8. Out of this comparative study, the following elements can be highlighted:

- Regarding the condenser, the model $C D_{B}$ shows a slightly better thermal performance (i.e. it fits a little better the experimental data in terms of heat transfer in the condenser), but it induces much larger scattering in the global mass calculation (i.e. larger standard deviations of $M_{w f, t o t}$ ) whatever the identification method employed to find the convective coefficients.

- Regarding the evaporator and the recuperator, the type of correlations used to simulate the BPHEXs does not influence much the mass inventory calculation once an identification method is applied to the original correlation. The models $E V_{A}$ and $R E C_{A}$ (i.e. the ones based on Martin's, Amalfi's and Longo's correlations) demonstrate slightly better results.

- In all situations, the homogenous and the Hughmark's void fraction models lead to the lowest and the highest mass estimations, respectively. On average, the difference between their total mass predictions is $2.54 \mathrm{~kg}$. On the other hand, the void fractions proposed by Zivi, Lockhart-Martinelli and Premoli lead to intermediate charge inventories. Whatever the identification method and the heat transfer correlations employed, Hughmark's void fraction model (which accounts for the influence of the fluid mass flux) appears to be the best modelling approach. In every case, it leads to the lowest error in the prediction of the charge and to the lowest standard deviation.

- The mass standard deviation is not much influenced by the void fraction model, but rather by the identification method applied to find the convective heat transfer coefficients. As shown in the previous section, the larger the modifications applied to the original correlations, the better the fitting of the heat power transferred in the heat exchangers. However, as shown in Fig. 8, the larger these modifications, the wider the scattering in the mass predictions. By altering the state-of-the-art correlations, the thermal performance of the heat exchanger models is improved but the charge inventory predictions are deteriorated.

Out of this study, it appears that the best modelling choices to simulate the heat exchangers is the void fraction proposed by Hughmark, the model $C D_{A}$ for the condenser and the models $E V_{A} / R E C_{A}$ for the brazed plate heat exchangers (cfr Table 4). Regarding the method used to identify the heat transfer coefficients, a trade-off must be made between the thermal performance and the charge inventory predictions of the heat exchanger models. So far, it is unclear which criteria is the most important to perform charge-sensitive simulations of a ORC system. Indeed, it might be valuable to give more credit to one criteria over the other if its influence was demonstrated to be more important for the simulation of the closed-loop system. To assess this point, it is required to simulate the entire ORC power system and to confront the model predictions with the experimental data.

\section{Other components modelling}

In order to simulate the entire ORC power system, other models are required to characterize the rest of the components. The following section presents the models used to simulate the scroll expander, the
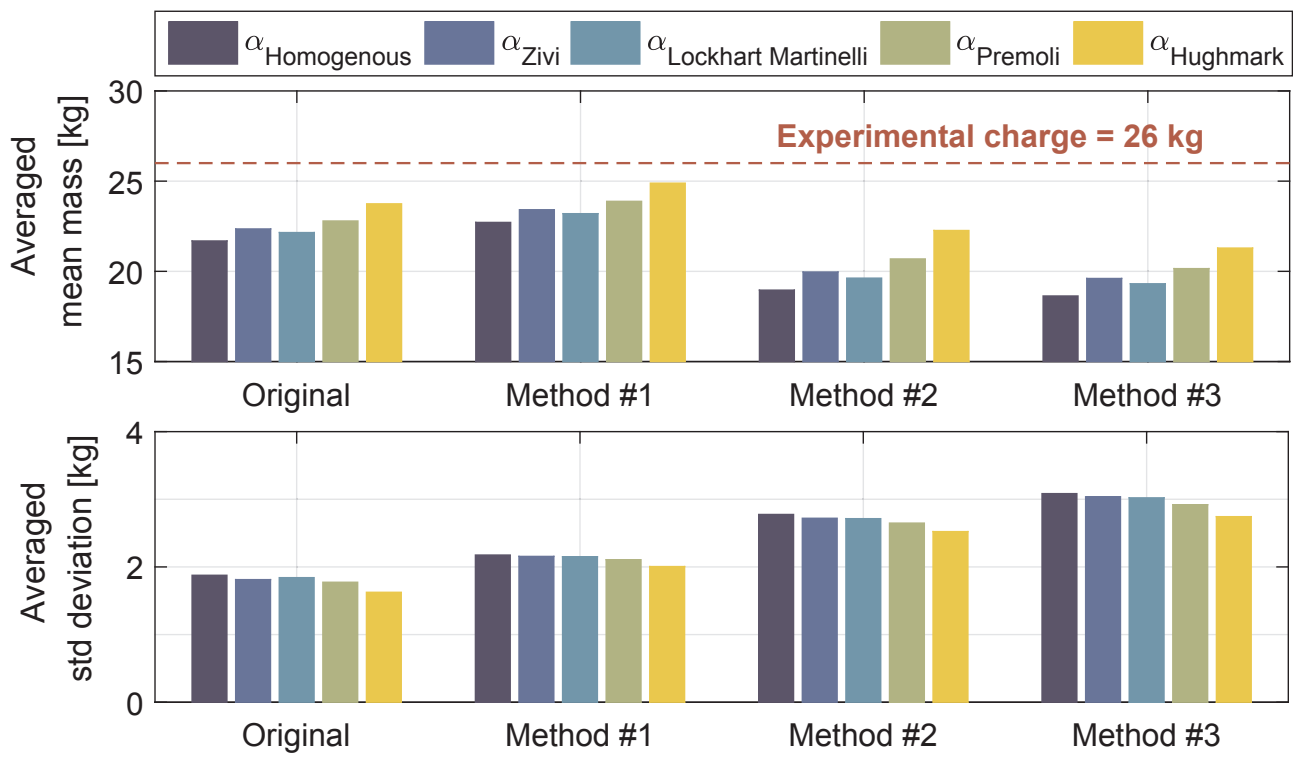

Fig. 8. Averaged results of the global charge predictions (in terms of mean mass and standard deviation) in function of the void fraction model employed and the tuning method applied to the convective heat transfer correlations. This figure summarizes the detailed results provided in Appendix C. 
diaphragm pump, the pipings and the liquid receiver.

\subsection{Mechanical devices}

Both the pump and the expander are simulated with semi-empirical models. This kind of model relies on a limited number of meaningful equations that describe the most significant phenomena occurring in the process. Such a modelling approach offers a good compromise between calibration efforts, simulation speed, modelling accuracy and extrapolation capabilities [11]. More specifically, the scroll expander is simulated by means of the grey-box model proposed by Lemort et al. [59]. Besides of under- and over-expansion losses (due to the fixed built-in volumetric ratio of the scroll expander), this model accounts for heat transfers and pressure drops at the inlet and outlet ports of the machine, mechanical losses, internal leakages and heat losses to the environment. The pump is modelled in a similar way with the model proposed in [60]. The pump model accounts for ambient losses, internal leakages, mechanical losses and cavitation phenomena (as proposed by Landelle et al. [61]).

For an extensive description of the models equations, please refer to the corresponding references. The parameters of these two semi-empirical models are calibrated to fit the experimental measurements. Regarding the charge modelling, the mass of working fluid enclosed in the two mechanical components is simply computed assuming a fluid mean density (Eq. (A.6)). The volume $V_{\text {mec }}$ is computed as the sum of the swept and the discharge volumes of these machines (retrieved from the components datasheet). This simplified approach is justified by the relatively small internal volumes in the mechanical components.

\subsection{Liquid receiver}

The liquid receiver (LR) is a single tank placed at the condenser outlet and used as a buffer reservoir. As demonstrated below, its goal in normal conditions is to ensure a saturated liquid state at the condenser outlet and to damp mass transfer in off-design conditions. In this work, the modelling of the liquid receiver neglects heat losses to the environment and hydrostatic effects due to the height of liquid (i.e. the pressure is assumed uniform through the liquid receiver). Therefore, the tank is thermodynamically passive for the working fluid and the equations used to model the liquid receiver are simply:

$h_{s u, L R}=h_{e x, L R}$

$P_{s u, L R}=P_{e x, L R}$

The mass of fluid stored in the reservoir is not straightforward to assess. Indeed, the level of liquid (defined as $L_{L R}=V_{l} / V_{L R}$ ) varies in function of the operating conditions and directly influences the amount of refrigerant enclosed in the tank. In order to predict the level of liquid in the receiver, the model is based on the following hypotheses:

1. In stabilized regimes, the presence of a partial liquid level (i.e. $\left.L_{L R} \in\right] 0,1[$ ) imposes the enclosed fluid to be in two-phase equilibrium.

2. Due to gravity and the absence of any entrainment effect, saturated liquid lays at the bottom of the tank while vapour remains at the top.

3. If there is a liquid level, only a liquid phase can be extracted since the extraction port is placed at the bottom of the tank (dip tube, as depicted in Fig. 9).

4. In steady-state conditions, the liquid level is constant and the mass balance implies an equality between the supply and the exhaust mass flow rates, i.e.

$\dot{m}_{s u, L R}=\dot{m}_{e x, L R}$
Although trivial individually, the combination of these four postulates leads to one important feature of the system: in steady-state operation (and in the absence of non-condensing gases), a liquid receiver may be a partially filled (i.e. $\left.L_{L R} \in\right] 0,1$ [) only if a saturated liquid enters and leaves the reservoir. Indeed, if a sub-cooled fluid is supplied to the tank, a two-phase equilibrium cannot exist (cfr. postulate 1) and the liquid reservoir must be filled by sub-cooled fluid. If a superheated vapour enters the receiver, the same conclusion can be drawn. Finally, if a two-phase mixture enters the reservoir (e.g. with a fluid quality $x_{s u, L R}=0.2$ ), a liquid-vapour equilibrium could exist. However, the exhaust port extracting a saturated liquid only (cfr. postulate 3 ), the receiver mass balance would be violated (since $x_{e x, L R}=0$ ). In order respect the fourth postulate, a liquid phase cannot reside in the tank and the reservoir must be filled of saturated vapour fluid. Based on this analysis, the mass of working fluid in the receiver is calculated as follows:

$M_{L R}= \begin{cases}V_{L R} \cdot \rho_{s u, L R} & \text { if } h_{s u, L R}<h\left(x=0, P=P_{s u, L R}\right) \\ V_{L R} \cdot\left[L_{L R} \cdot \rho_{l}+\left(1-L_{L R}\right) \cdot \rho_{v}\right] & \text { if } x_{s u, L R}=0 \\ V_{L R} \cdot \rho_{v} & \left.\left.\text { if } x_{s u, L R} \in\right] 0,1\right] \\ V_{L R} \cdot \rho_{s u, L R} & \text { if } h_{s u, L R}>h\left(x=1, P=P_{s u, L R}\right)\end{cases}$

where $L_{L R}$ is the liquid level and $\rho_{l}$ (resp. $\rho_{v}$ ) is the saturated liquid (resp. vapour) density of the fluid at the supply pressure. It is important to note that under normal operating conditions, the receiver is intended to be partially filled of liquid and it imposes a fluid subcooling of zero at the condenser outlet. In such conditions, the level of liquid $L_{L R}$ is given by the over amount of working fluid that is not spread in the rest of the system. If the charge of fluid is not properly chosen or if the ORC system is operating in strong off-design conditions, the receiver can be completely flooded or emptied. For a given operating pressure, Fig. 10 illustrates the mass of refrigerant enclosed in the liquid receiver as a function of the fluid supply enthalpy. It can be seen that a large discontinuity in the mass profile occurs when the fluid reaches its saturated liquid state (i.e. $x_{s u, L R}=0$ ). As further discussed in Section 5 , this discontinuity leads to numerical issues when modelling the entire ORC system. Finally, in the test rig investigated here, cavitation problems with the diaphragm pump imposed to voluntarily over-charge the system of working fluid to ensure a minimum fluid subcooling. Therefore, most of the points included in the experimental dataset feature a flooded liquid receiver.

\subsection{Piping}

Besides the active components constituting the ORC system, pressure drops and heat losses induced by the interconnecting pipelines are also taken into account. These losses are lumped in the high- and the low-pressure lines by means of single artificial components placed at the outlet of the evaporator and the condenser, respectively. The

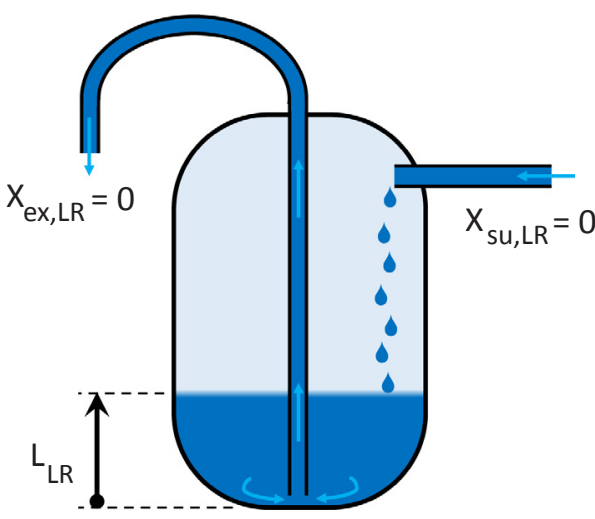

Fig. 9. Scheme of the liquid receiver. 


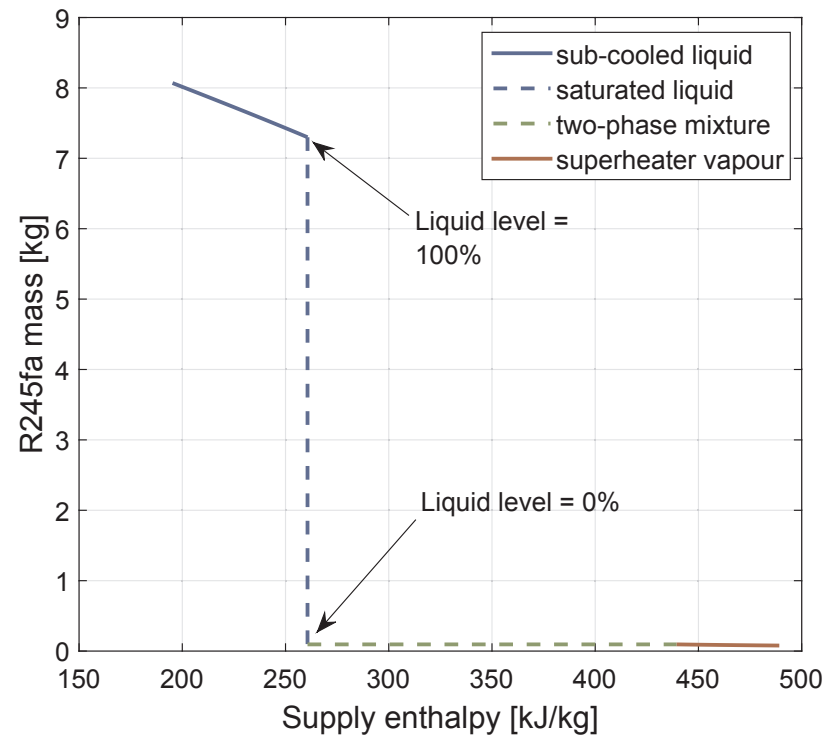

Fig. 10. Mass enclosed in the liquid receiver as a function of the fluid supply enthalpy (for a supply pressure of 3 bar).

pressure losses are computed as a linear function of the fluid kinetic energy (Eq. (A.7)) while ambient heat losses are modelled with a single empirical heat transfer coefficient (Eq. (A.8)) The mass of working fluid enclosed in every section of interconnecting pipes is also taken into account (Eq. (A.9)).

\section{ORC system modelling}

The model of the entire ORC system is obtained by coupling in series the models describing each subcomponent. As depicted in Fig. 11, the ORC model is built in such a way that the unit performance is derived from its boundary conditions only. These boundary conditions are chosen to be exactly the same as seen in practice by the test rig, namely

- the heat source supply conditions $\left(T_{h t f, h, s u}, P_{h t f, h, s u}, \dot{m}_{h t f, h}\right)$;

- the heat sink supply conditions $\left(T_{h t f, c, s u}, P_{h t f, c, s u}, \dot{m}_{h t f, c}\right)$;

- the ambient temperature;

- the rotational speeds of the mechanical components (e.g. pump and expander);

- the components geometry;

- the total mass of refrigerant in the system;

Apart of these inputs and the parameters characterizing each component, the ORC model does not rely on any user-specified assumption in the cycle state (e.g. an imposed subcooling, superheating, mass flow rate, operating pressure or temperatures, etc.).

Such modelling of a closed-loop system is highly implicit because of the multiple interactions between the working fluid states, the different components performance and the system boundary conditions. Therefore, the thermodynamic state of the engine cannot be computed straightforwardly but it is found through an optimization aiming to drive internal modelling residuals to zero. More specifically, the ORC model iterates on the evaporator outlet enthalpy $\left(i t_{1}=h_{e v, e x}\right.$ ), the evaporating pressure $\left(i t_{2}=P_{p p, e x}\right)$, the condensing pressure $\left(i t_{3}=P_{p p, s u}\right)$ and the condenser outlet subcooling $\left(i t_{4}=\Delta T_{s c}\right.$ ) in order to decrease the following residuals below a predefined threshold $\left(10^{-6}\right)$ :

$r e s_{1}=1-\frac{N_{\exp , 2}}{N_{\text {exp }}}$

$r e s_{3}=1-\frac{h_{c d, e x, 2}}{h_{c d, e x}}$

$r e s_{3}=1-\frac{h_{e v, e x, 2}}{h_{e v, e x}}$

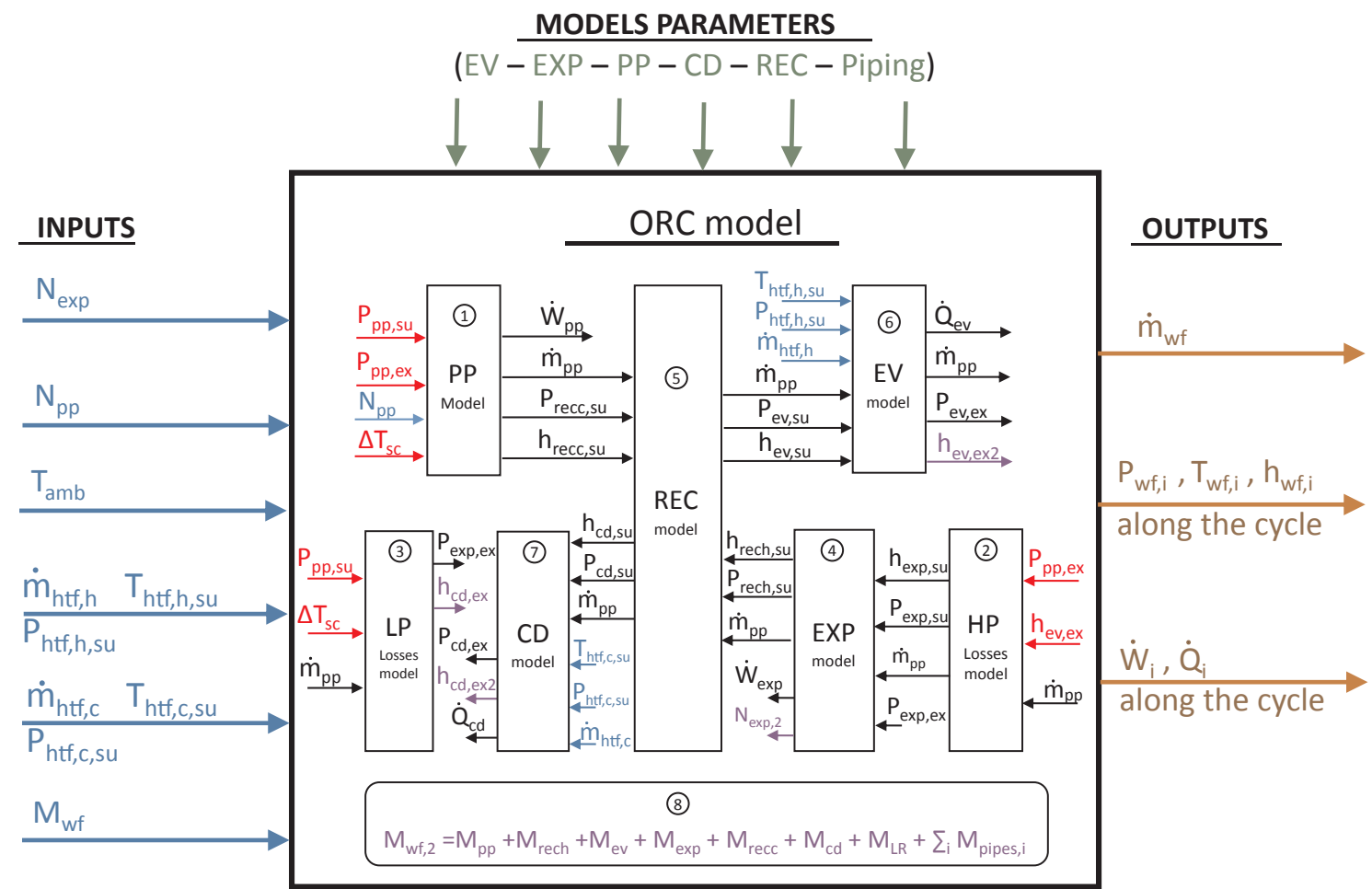

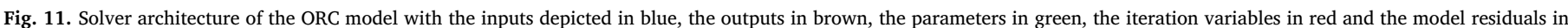

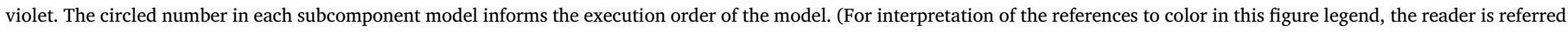
to the web version of this article.) 
res $_{4}=1-\frac{M_{w f, 2}}{M_{w f, t o t}}$

For a better understanding of the sub-models interaction, the architecture of the ORC model is depicted in Fig. 11. When the ORC system features a liquid receiver, the numerical resolution of this 4dimension problem is uneasy because of convergence issues. For increased robustness, a two-stage solver is developed to perform chargesensitive simulations. A detailed description of this solver is presented in Appendix D

\section{Model validation and discussion}

In this section, the ORC model is validated by simulating the complete test rig in the exact same conditions as the 40 reference points of the experimental dataset. To this end, only the boundary conditions of the test rig are provided as inputs to the ORC model. The resulting state predicted for the entire system is then confronted to the experimental measurements. The ORC model is tested with the three identification methods investigated to calculate the convective heat transfer coefficients in the HEXs (cfr. Section 3). Furthermore, to emphasize the effect of imposing the charge in the ORC model instead of the fluid subcooling, the results of the charge-sensitive model are compared to the predictions obtained when the subcooling is imposed to 3 different values (i.e. the mean, the lowest and the highest subcooling reached experimentally, equal to $13 \mathrm{~K}, 4 \mathrm{~K}$ and $23 \mathrm{~K}$ respectively). For the sake of simplicity, the model outputs are only compared in terms of the system net thermal efficiency, i.e.

$\eta_{n e t, O R C}=\frac{\dot{W}_{\text {exp }}-\dot{W}_{p p}-\dot{W}_{c d}}{\dot{Q}_{e v}}$

where $\dot{W}_{p p}$ and $\dot{W}_{c d}$ are the pump and the condenser fan consumptions, $\dot{W}_{\text {exp }}$ is the expander power generation, and $\dot{Q}_{e v}$ is the heat transfer rate in the evaporator. The mean percent error committed by the different models when predicting this net thermal efficiency is depicted in Fig. 12. Out of this figure, the following conclusions may be derived:

- A poor characterization of the fluid subcooling as a significant impact on the modelling of the ORC power system, especially if the subcooling is overpredicted. On average, an overestimation (resp. underestimation) of the subcooling of $1 \mathrm{~K}$ relatively decreases (resp. increases) the prediction of the ORC net thermal efficiency by $3 \%$.

- When the fluid subcooling is imposed, the more the original heat transfer correlations are changed (method \#1 $\rightarrow \# 3$ ), the better the ORC model predictions. This observation is totally in accordance with the results presented in Section 3.1 since these identification methods increasingly better fit the heat transfer in the heat exchangers.

- When the total charge of working fluid is imposed, however, the opposite trend is seen: the more the convective heat transfer coefficients are changed, the poorer the ORC model predictions. For the system net thermal efficiency, the mean percent error committed by the ORC model when using the identification methods \#1, \#2 and \#3 is equal to $11.6 \%, 28.8 \%$ and $44.2 \%$ respectively. According to the results shown in Section 3.1, such high residuals are due to an improper modelling of the mass enclosed in the various heat exchangers. Consequently, it can be concluded that a proper estimation of the mass enclosed in the heat exchangers is much more important that a slight gain in the heat transfer predictions.

Based on these results, one may think that if the fluid subcooling was well known (e.g. $\Delta T_{s c}$ would not change in function of the operating conditions and could be imposed in the ORC model), the best identification method would be the \#3 since it shows the lowest residuals. This conclusion is wrong. Indeed, the results in Fig. 12 only illustrate the ability of the ORC models to fit a dataset while their true purpose is to reliably predict the system performance in unseen conditions. The charge-sensitive results (in which the mass is imposed instead of the subcooling) show that the convective heat transfer coefficients given by the methods \#2 and \#3 do not predict properly the zones distribution in the heat exchangers. Since these coefficients fail to replicate the phenomena occurring inside the heat exchangers, the extrapolability of these HEX models (and, by extension, of the ORC model too) is not guaranteed. As mentioned in Section 3.1, the modelling of the heat exchangers is somehow problematic because different combinations of convective heat transfer coefficients may lead to similar heat transfer predictions. As demonstrated here, the modelling of the charge provides a new criteria to better assess the reliability of the convective heat transfer coefficients used to describe the heat exchangers. Taking the charge into account helps to reduce overfitting issues.

The most suited identification method to be applied to the state-ofthe-art correlations is the method \#1. By only scaling one heat transfer correlation (the one referring to the highest thermal resistivity in the heat transfer), this tuning method efficiently improves the thermal predictions in the heat exchanger model while ensuring a proper mass evaluation in the ORC system. For the case study investigated here, the parameters used to simulate the heat exchangers are summarized in Table 5. Additionally, parity plots of some key model outputs are depicted in Fig. 13. It can be seen that the ORC model predicts well the thermal power transferred in the heat exchangers with a mean percent error lower than $2 \%$. Regarding the mechanical powers of the pump and the expander, larger deviations are observed (mean percent error $<11.5 \%$ ) because of the higher sensitivity to deviations in the cycle pressures. However, the points showing the largest deviations are also the most sensitive to the uncertainty in the total charge of working fluid (known to be $26 \mathrm{~kg} \pm 0.5 \mathrm{~kg}$ ). Finally, the mean percent error committed on net thermal efficiency prediction is $11.6 \%$. Considering the accumulation of errors and the absence of any intrinsic assumption in the system state to compute this efficiency, such an error is found acceptable. This charge-sensitive model can therefore be used to reliably predict the ORC system behaviour in off-design conditions based on its boundary conditions only.

\section{Conclusion}

The present work focuses on the development and the validation of a charge-sensitive ORC model to be used for off-design performance simulations. A $2 \mathrm{kWe}$ recuperative ORC unit is used as case study and experimental data are exploited to validate the models. The goal is to

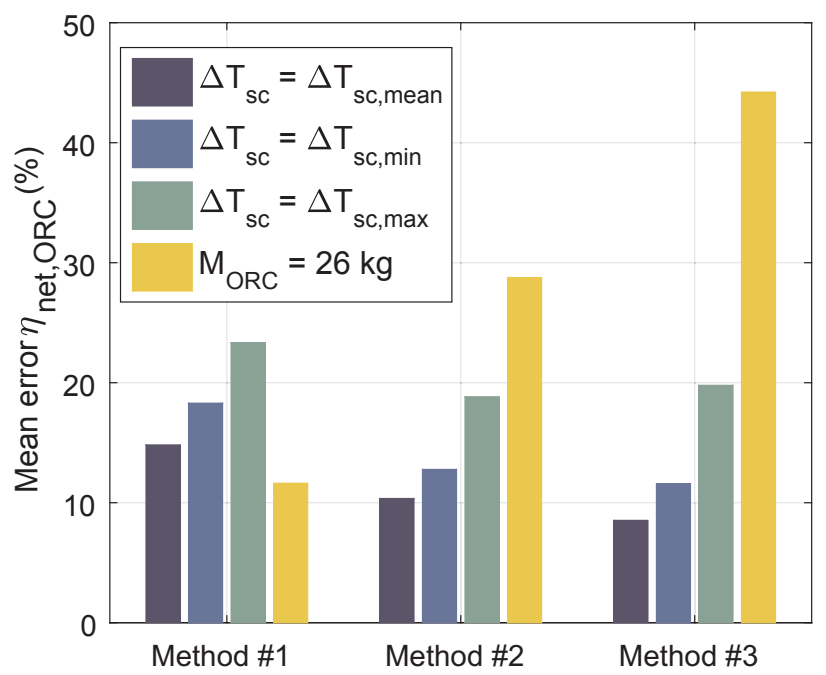

Fig. 12. Mean Absolute Percent Error (MAPE) committed on the net ORC efficiency in function of the identification method applied to simulate the HEXs and the subcooling/ mass imposed in the ORC model. 
Table 5

Parameters of the charge-sensitive HEX models.

\begin{tabular}{c}
\hline Evaporator \\
\hline $\begin{array}{c}\text { Single-phase correlation: Martin (with } c=0.268) \\
\text { Boiling correlation: Amalfi et al. (unchanged) } \\
\text { Void fraction: Hughmark }\end{array}$ \\
\hline Recuperator \\
\hline Cingle-phase correlation: Martin (with $c=0.6557)$ \\
Condensation correlation: Longo et al. (unchanged) \\
Coid fraction: Hughmark \\
Condenser \\
Air-side correlation: VDI (with $c=0.896)$ \\
Single-phase correlation: Gnielinski (unchanged) \\
Condensation correlation: Cavallini et al. (unchanged) \\
Void fraction: Hughmark
\end{tabular}

develop a reliable model which only accounts for the system boundary conditions (i.e. the heat source/heat sink supply conditions, the mechanical components rotational speeds, the ambient temperature and the total charge of working fluid) to predict the ORC system performance. To this end, models are developed to characterize each subcomponents and they are assembled to simulate the entire closed-loop system. The heat exchanger modelling is investigated in detail and three different methods are tested to calculate the convective heat transfer coefficients. Out of this study, the main outcomes can be summarized as follows:

- For performing charge-sensitive simulations, it is mandatory to properly predict the mass of fluid enclosed in the various heat exchangers. If several zones of fluid co-exist in a same component, this implies a good modelling of the spatial distribution occupied by the different zones. The identification of the convective heat transfer coefficients (which directly impact the zones distribution) is uneasy without dedicated experiments and state-of-the-art correlations should be used as initial guesses.

- Among nine different convective heat transfer correlations, the single-phase correlation of Martin [38], the condensing correlation of Longo et al. [44] and the boiling correlation of Amalfi et al. [41] are shown to be good candidates for characterizing the BPHEXs. Regarding the fin coil condenser, the air-side heat transfer correlation given in [47] is the best option. However, these correlations should only be considered as initial guesses to calculate the effective convective heat transfer coefficients. In order to better represent the thermal performance of the HEXs, the correlations parameters can be re-tuned by means of an identification method (mandatory in this case for the BPHEXs).

- When re-identifying the parameters of the convective heat transfer correlations, the heat transfer predictions of the HEX models are improved but the charge inventory of the global system is deteriorated.

- Among the three identification methods investigated for the case study, the least intrusive (i.e. method \#1) is the best to retrieve the convective heat transfer coefficients in the heat exchangers. By only scaling one convective heat transfer coefficient (the one referring to the highest thermal resistivity in the heat transfer), this identification method efficiently fits the thermal performance of the heat exchangers while ensuring a proper global charge estimation in the ORC system. Furthermore, when modelling the entire ORC system, it is shown that a proper estimation of the mass enclosed in the heat exchangers is more important than a slight improvement of the heat transfer predictions.
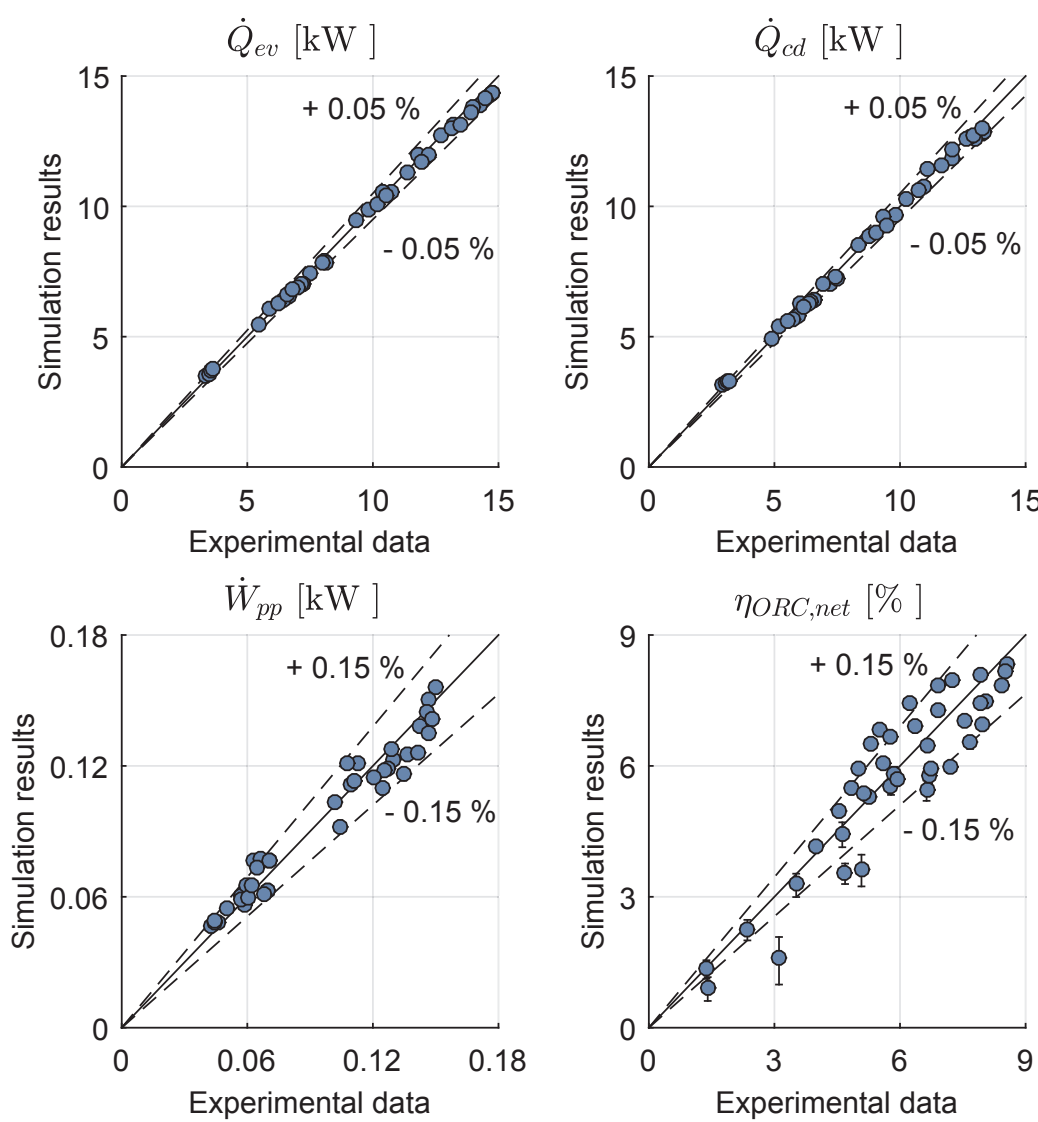

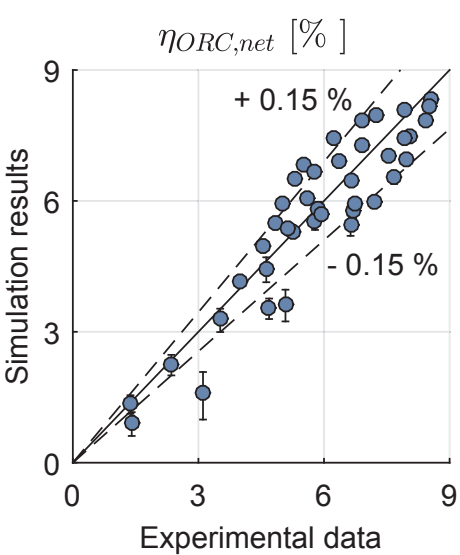

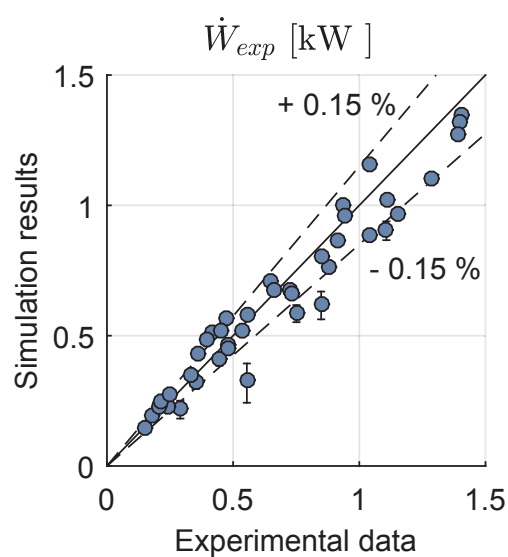

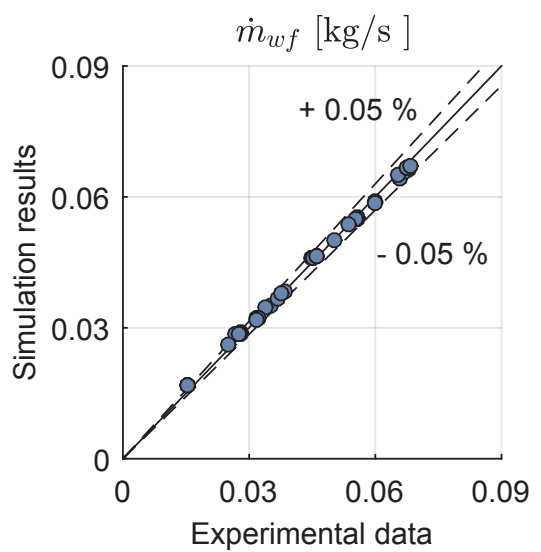

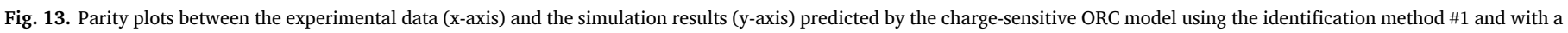
total charge of $26 \mathrm{~kg}$ (the vertical bars account for the $\pm 0.5 \mathrm{~kg}$ uncertainty of the experimental charge). 
- Among five different candidates, the best void fraction model identified is the one proposed by Hughmark [58] which accounts for the influence of the working fluid mass flux. It is worth mentioning that similar analyses applied to HVAC systems (e.g. [21,19]) also identified this model to be the best option for characterizing the fluids void fraction.

- If not properly handled numerically, the presence of a liquid receiver in the ORC system may lead to convergence issues when performing charge-sensitive simulations. To overcome this problem, a dedicated two-stage solver is developed to ensure high robustness.

- The mean percent errors committed by the charge-sensitive ORC model to fit the thermal power in heat exchangers, the mechanical powers in the pump/expander and the net thermal efficiency are respectively lower than $2 \%, 11.5 \%$ and $11.6 \%$. Furthermore, the points showing the largest deviations are also the most sensitive to the uncertainty in the total charge of working fluid (26 kg \pm $0.5 \mathrm{~kg}$ ).

- Even for subcooling-sensitive ORC models, the modelling of the charge in the system is interesting because it helps to prevent

\section{Appendix A. Models constitutive equations}

$\dot{Q}_{i}=A_{i} U_{i} \Delta T_{\text {log }, i}$

$U_{i}=\left(\frac{1}{H_{h, i}}+\frac{1}{H_{c, i}}\right)^{-1}$

$\sum_{i=1}^{N} A_{i}=A_{H E X}$

$\sum_{i=1}^{N} \omega_{i}=1$

$\omega_{i}=\frac{A_{i}}{A_{H E X}}$

$M_{m e c}=V_{m e c} \frac{\rho_{\text {su,mec }}+\rho_{e x, m e c}}{2}$

$\Delta P_{\text {pipe }}=K\left(\frac{\dot{m}^{2}}{\rho_{\text {su,pipe }}}\right)+B$

$\dot{Q}_{\text {pipe }}=A U_{\text {pipe }}\left(T_{\text {su,pipe }}-T_{\text {amb }}\right)$

$M_{\text {pipe }}=V_{\text {pipe }} \rho_{\text {su,pipe }}$

Appendix B. State-of-the-art correlations

\section{B.1. Single-phase in BPHEXs}

\section{- $\underline{\text { Martin }}$ [38]}

$N u=c_{1} \cdot 0.205 \cdot \operatorname{Pr}^{1 / 3}\left(f \cdot R e^{2} \cdot \sin (2 \theta)\right)^{c_{2} * 0.374}$

$\frac{1}{\sqrt{f}}=\frac{\cos (\theta)}{\sqrt{0.045 \tan (\theta)+0.09 \sin (\theta)+f_{0} / \cos (\theta)}}+\frac{1-\cos (\theta)}{\sqrt{3.8 f_{1}}}$

$$
f_{0}= \begin{cases}16 / R e & \text { if } R e \leqslant 2000 \\ (1.56 \ln R e-3)^{-2} & \text { if } R e>2000\end{cases}
$$

overfitting issues when identifying the convective heat transfer coefficients used to describe the heat exchangers.

To conclude, it is worth mentioning that the current validation is performed using only the global charge of refrigerant in the system. In order to fully validate the HEX models and the charge inventory predictions, experimental measurements of the mass repartition between the different components would be required. Future works involve such investigations. Ultimately, the proposed models will be used to better characterize and to optimize the performance of ORC systems over a wide range of off-design conditions.

\section{Acknowledgements}

R. Dickes thanks the Fund for Scientific Research of Belgium (F.R.S F.N.R.S) for its financial support (research fellowship FC2349). The authors also would like to gratefully acknowledge the contributors to the Sun2Power project (CMI group, Enertime, Emerson, ACTE and Honeywell). 


$$
f_{1}= \begin{cases}149.25 / R e+0.9625 & \text { if } R e \leqslant 2000 \\ 9.75 / R e^{0.289} & \text { if } R e>2000\end{cases}
$$

- Wanniarachchi et al. [39]

$$
\begin{aligned}
& N u=c_{1}\left(j_{\text {lam }}^{3}+j_{\text {turb }}^{3}\right)^{1 / 3} \mathrm{Pr}^{1 / 3} \\
& j_{\text {lam }}=3.65(\pi / 2-\theta)^{-0.455} \mathrm{Re}^{-0.339 \cdot c_{2}} \\
& j_{\text {turb }}=\frac{12.6}{(\pi / 2-\theta)^{1.142}} \operatorname{Re}^{c_{2}(0.646+0.00111(\pi / 2-\theta))}
\end{aligned}
$$

- Thonon [40]

$$
N u=c_{1} \cdot C \cdot R e^{m \cdot c_{2}} \operatorname{Pr}^{1 / 3}
$$

$$
\begin{aligned}
& * \theta=15 \rightarrow C=0.1000 \mathrm{I} m=0.687 \\
& * \theta=30 \rightarrow C=0.2267 \mathrm{I} \mathrm{m}=0.631 \\
& * \theta=45 \rightarrow C=0.2998 \mathrm{Im}=0.645 \\
& * \theta=60 \rightarrow C=0.2946 \mathrm{Im}=0.700
\end{aligned}
$$

\section{B.2. Evaporation in BPHEXs}

- Amalfi et al. [41]

$$
N u= \begin{cases}c_{1} \cdot 982\left(\frac{\theta}{\theta_{\max }}\right)^{1.101} W e^{\left(0.315 \cdot c_{2}\right)} B o^{0.32}\left(\frac{\rho_{l}}{\rho_{v}}\right)^{-0.224} & \text { if } B d \leqslant 4 \quad \text { (B. 13) } \\ c_{1} \cdot 18.495\left(\frac{\theta}{\theta_{\max }}\right)^{0.248} R e_{v}^{0.135 c_{2}} R e_{l o}^{0.351 c_{2}} B d^{0.235} B 0^{0.198}\left(\frac{\rho_{l}}{\rho_{v}}\right)^{-0.223} & \text { if } B d>4 \quad \text { (B. 14) }\end{cases}
$$

- Han et al. [42]

$\mathrm{Nu}=c_{1} \cdot C \cdot \operatorname{Re}^{c^{2} \cdot m} \mathrm{Bo}^{0.3} \mathrm{Pr}^{0.4}$

$C=2.81\left(p_{c o} / D_{h}\right)^{-0.041} \theta^{-2.83}$

$m=0.746\left(p_{c o} / D_{h}\right)^{-0.082} \theta^{0.61}$

- $\underline{\text { Cooper [43] }}$

$\frac{H}{(q / A)^{0.67 \cdot c_{2}}}=c_{1} \cdot 55 P_{\text {red }}^{(0.12-0.2 \log R p)}\left(-\log P_{\text {red }}\right)^{-0.55 \cdot c_{2}} M M^{-0.5}$

B.3. Condensation in BPHEXs

- Longo et al. [44] 


$$
N u=c_{1} \cdot 0.943 \Phi \frac{L}{k}\left[\frac{k_{l}^{3} \rho_{l}^{2} g \Delta h_{l a t}}{\mu_{l} \Delta T L}\right]^{0.25} \quad \text { if } \quad R e \leqslant 1600
$$

$$
\mathrm{Nu}=c_{1} \cdot 1.875 \Phi \operatorname{Re}^{c_{2} \cdot 0.445} \mathrm{Pr}^{1 / 3} \quad \text { if } \quad \operatorname{Re}>1600
$$

- Han et al. [45]

$$
\mathrm{Nu}=c_{1} \cdot C \cdot \operatorname{Re}^{c_{2} \cdot m} \mathrm{Bo}^{0.3} \mathrm{Pr}^{1 / 3}
$$

$C=11.22\left(p_{c o} / D_{h}\right)^{-2.83} \theta^{-4.5}$

$$
m=0.35\left(p_{c o} / D_{h}\right)^{0.23} \theta^{1.48}
$$

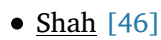

$$
N u=N u_{l}\left[(1-x)^{0.8}+\frac{3.8 x^{0.76}(1-x)^{0.04}}{P_{r e d}^{0.38}}\right]
$$

$N u_{l}=c_{1} \cdot 0.023 R e^{0.5 \cdot c_{2}} \operatorname{Pr}^{0.4}$

\section{B.4. Fin-coil condenser}

- Gnielinski [47]

$N u_{1}=4.364$

$N u_{2}=1.953 \sqrt[3]{\operatorname{Re} \cdot \operatorname{Pr} \cdot d_{i} / l}$

$f=(1.8 \log R e-1.5)^{-2}$

$\left.N u=c_{1} \cdot\left(N u_{1}^{3}+0.6^{3}+\left(N u_{2}-0.6\right)^{3}\right)\right)^{1 / 3} \quad$ if $R e<2300$

$$
N u=c_{1} \cdot \frac{(f / 8) R e \cdot P r}{1+12.7 \sqrt{f / 8}\left(\operatorname{Pr}^{2 / 3}-1\right)} \quad \text { if } \operatorname{Re}>2300
$$

- Cavallini et al. [48]: for the sake of conciseness, please refer to the corresponding paper.

- VDI [47]

$$
N u=c_{1} \cdot 0.38 \operatorname{Re}^{\left(c_{2} \cdot 0.6\right)} \Omega_{t}^{-0.15} \operatorname{Pr}^{1 / 3}
$$

- Wang [49]: for the sake of conciseness, please refer to the corresponding paper.

\section{B.5. Void fraction}

- Homogenous:

$$
\alpha=\left(1+\frac{1-x}{x}\left(\frac{\rho_{v}}{\rho_{l}}\right)\right)^{-1}
$$

\section{- Zivi [55]:}




$$
\alpha=\left(1+\frac{1-x}{x}\left(\frac{\rho_{v}}{\rho_{l}}\right)^{-2 / 3}\right)^{-1}
$$

- Lockhart-Martinelli [56]:

$$
\alpha= \begin{cases}\left(1+X_{t t}^{0.8}\right)^{-0.378} & \text { if } X_{t t} \leq 10 \\ 0.823-0.157 \ln \left(X_{t t}\right) & \text { if } X_{t t}>10\end{cases}
$$

- Premoli [57]:

$$
\begin{aligned}
& \alpha=\left(1+\frac{1-x}{x}\left(\frac{\rho_{v}}{\rho_{l}}\right) S\right)^{-1} \\
& S=1+F_{1}\left[\frac{y}{1+y F_{2}}-y F_{2}\right]^{0.5} \\
& F_{1}=1.578 \cdot R e^{-0.19}\left(\frac{\rho_{l}}{\rho_{v}}\right)^{0.22} \\
& F_{2}=0.0273 \cdot W e \cdot R e^{-0.51}\left(\frac{\rho_{l}}{\rho_{v}}\right)^{-0.08} \\
& y=\frac{x \rho_{l}}{(1-x) \rho_{v}}
\end{aligned}
$$

\section{- Hughmark [58]}

$$
\alpha=K_{H} \cdot \beta
$$

$$
\ln K_{H}=\sum_{i=0}^{4} K_{i}(\ln Z)^{i}
$$

$Z=\left[\frac{D_{h} G}{\mu_{l}+\alpha\left(\mu_{v}-\mu_{l}\right)}\right]^{1 / 6}\left[\frac{1}{g D_{h}}\left(\frac{G x}{\rho_{v} \beta(1-\beta)}\right)\right]^{1 / 8}$

$$
\beta=\left(1+\frac{1-x}{x}\left(\frac{\rho_{v}}{\rho_{l}}\right)\right)^{-1}
$$

$\mathbf{K}=[-0.2306 ; \quad 2.384 ; \quad-1.031 ; \quad 0.1994 ; \quad-0.0141]$

\section{Appendix C. HEX modelling - Global results}

The global results of the HEX modelling section are given in Fig. C.14. This figure depicts the results when combining all the different HEX models in terms of heat transfer and charge inventory predictions. Each abscissa (from 1 to 72) is referring to a unique combination of BPHEX model $\left(E V_{A} / R E C_{A} \rightarrow E V_{I} / R E C_{I}\right)$, condenser model $\left(C D_{A}\right.$ or $\left.C D_{B}\right)$ and identification method (original correlations or with tuning method \#1 to \#3). The 3 top 


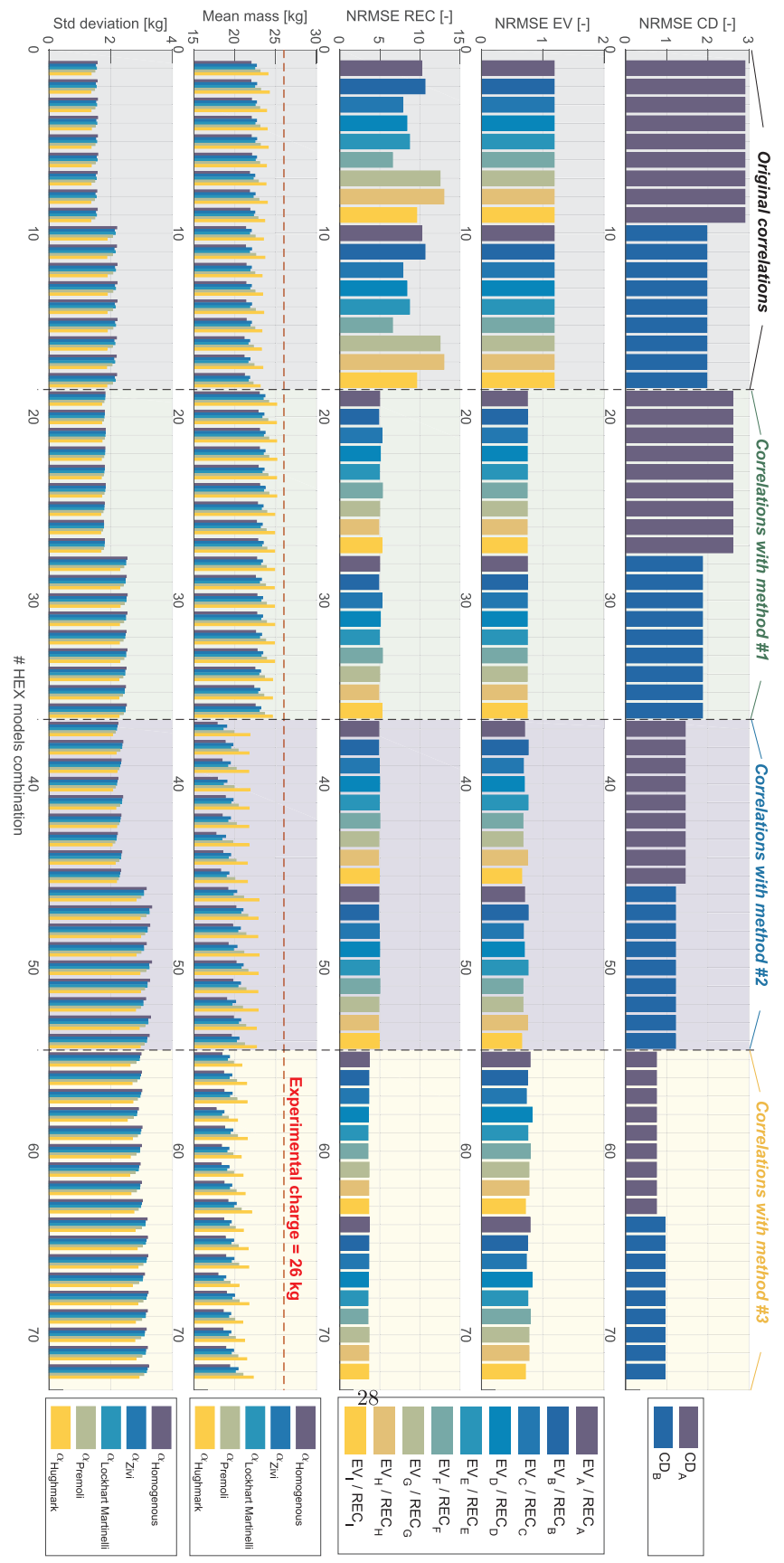

Fig. C.14. Global results of the HEX modelling study (cfr. Section 3).

subplots depict the NRMSE (as defined in Eq. (6)) committed on the heat transfer prediction of each heat exchangers. The 4th subplot depicts the mean total mass predicted over the 40 experimental points (aimed to be close to the experimental charge $26 \pm 0.5 \mathrm{~kg}$ ). The 5th subplot illustrates the standard deviation of the global mass prediction over the dataset (aimed to be as low as possible).

\section{Appendix D. ORC model solver}

As explained in Section 5, the ORC model requires to iterate on four variables in order to drive four residuals to zero. The four iterative variables are the evaporator outlet enthalpy $\left(i t_{1}=h_{e v, e x}\right.$ ), the evaporating pressure ( $i t_{2}=P_{p p, e x}$ ), the condensing pressure $\left(i t_{3}=P_{p p, s u}\right)$ and the condenser outlet subcooling $\left(i t_{4}=\Delta T_{s c}\right.$ ), while the four residuals are the expander rotational speed (res ${ }_{1}$ in Eq. (15)), the condenser outlet enthalpy $\left(r e s_{2}\right.$ in Eq. (16)), the evaporator outlet enthalpy (res 3 in Eq. (17)) and the total charge of refrigerant (res 4 in Eq. (18)). If a liquid receiver is present in the system, a direct resolution of this 4-dimension problem with a single multivariate algorithm often leads to convergence issues. Indeed, the total mass of fluid is one of the residuals while the pump supply conditions (identical to those in the liquid receiver) are part of the iteration variables. As highlighted in Section 4, a sharp discontinuity occurs in the mass profile enclosed by the liquid receiver when the fluid reaches a saturated liquid state. This discontinuity in the residual res $_{4}$ is detrimental for standard multi-dimensional solvers which generally fail to recognize situations where a liquid level lays in the receiver. For increased robustness, it is proposed to resolve the ORC model by means of a two-stage solver as depicted in Fig. D.15. Instead of iterating in parallel on the four variables $i t_{1 \rightarrow 4}$ so as to minimize the four residuals res $s_{1 \rightarrow 4}$, it is chosen to independently iterate on the fluid 


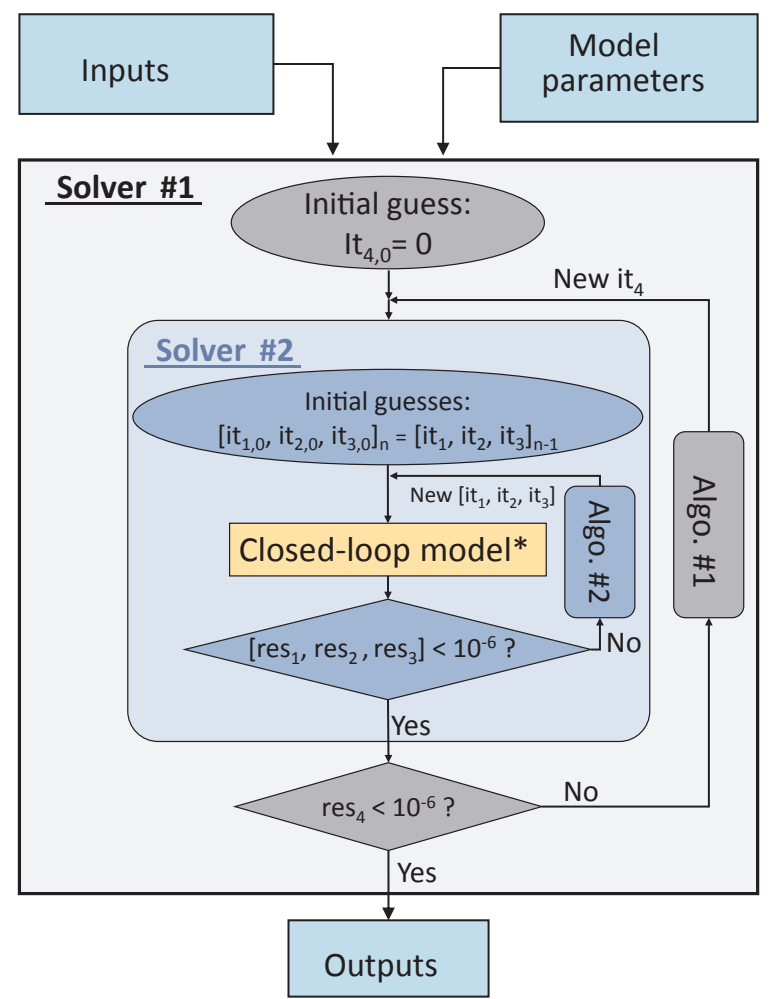

Fig. D.15. Architecture of the two-stage solver for performing robust charge-sensitive simulations.

subcooling $\left(i t_{4}\right)$ so as to retrieve the global charge of working fluid $\left(r e s_{4}\right)$. For every guess in the fluid subcooling (it $\left.t_{4}\right)$, a second solver is used to find the three other variables $i t_{1 \rightarrow 3}$ which minimize the residuals $r s_{1 \rightarrow 3}$. In other words, the charge-sensitive ORC model is built by iterating on a subcooling-sensitive ORC model. Such an approach is slower but much more robust. It permits to explicitly evaluate the situation where $\Delta T_{s c}=0$ and to check if the liquid receiver is partially filled or not. If the liquid receiver is flooded (or simply missing), the subcooling is updated iteratively until a proper mass distribution is found along the cycle. In order to maximize the simulation speed, intermediate results obtained for each guess on the fluid subcooling are used as initial guesses for the next iteration. The first-level solver (solver \#1, which iterates on the fluid subcooling) is an improved version of Brent's algorithm [62] decicated to this application. On the other hand, the second-level solver (solver \#2, which iterates on the two pressures and the evaporator outlet enthalpy), is a multivariate interior-point algorithm [52].

\section{References}

[1] Tchanche BF, Lambrinos G, Frangoudakis A, Papadakis G. Low-grade heat conversion into power using organic Rankine cycles - a review of various applications. Renew Sustain Energy Rev 2011;15(8):3963-79. URL < http://www.scopus.com/ inward/record.url?eid $=2$-s2.0-80051796336\&partnerID $=40 \&$ md5 $=$ e82c9ef56a54434195ce939c762d3f78>

[2] Quoilin S, Broek MVD, Declaye S, Dewallef P, Lemort V. Techno-economic survey of organic rankine cycle (ORC) systems. Renew Sustain Energy Rev 2013;22:168-86. http://dx.doi.org/10.1016/j.rser.2013.01.028.

[3] Macchi E, Astolfi M, editors. Organic Rankine Cycle (ORC) power systems - technologies and applications. elsevier ed.Woodhead Publishing Series in Energy; 2016.

[4] Gurgenci H. Performance of power plants with organic Rankine cycles under partload and off-design conditions. Solar Wind Technol 1986;36(1):45-51. http://dx. doi.org/10.1016/0038-092X(86)90059-9. URL < http://www.sciencedirect.com/ science/article/pii/0038092X86900599>.

[5] Wang J, Yan Z, Zhao P, Dai Y. Off-design performance analysis of a solar-powered organic Rankine cycle. Energy Convers Manage 2014;80:150-7. http://dx.doi.org/ 10.1016/j.enconman.2014.01.032.

[6] Hu D, Zheng Y, Wu Y, Li S, Dai Y. Off-design performance comparison of an organic Rankine cycle under different control strategies. Appl Energy 2015;156:268-79. http://dx.doi.org/10.1016/j.apenergy.2015.07.029. URL < http://www. sciencedirect.com/science/article/pii/S0306261915008582>.

[7] Manente G, Toffolo A, Lazzaretto A, Paci M. An Organic Rankine Cycle off-design model for the search of the optimal control strategy. Energy 2013;58:97-106. http://dx.doi.org/10.1016/j.energy.2012.12.035.

[8] Quoilin S. Sustainable energy conversion through the use of organic Rankine cycles for waste heat recovery and solar applications [Ph.D. thesis]. University of Liège; 2011.

[9] Lecompte S, Broek MVD, Paepe MD. Optimal part-load operation of an $11 \mathrm{kWe}$ organic Rankine cycle for waste heat recovery. In: Proceedings of ECOS 2016; 2016.

[10] Ibarra M, Rovira A, Alarcón-Padilla DC, Blanco J. Performance of a 5 kWe Organic Rankine Cycle at part-load operation. Appl Energy 2014;120:147-58. http://dx.doi. org/10.1016/j.apenergy.2014.01.057.

[11] Dickes R, Dumont O, Daccord R, Quoilin S, Lemort V. Modelling of organic Rankine cycle power systems in off-design conditions: an experimentally-validated comparative study. Energy 2017;123:710-27. http://dx.doi.org/10.1016/j.energy, 2017.01.130. URL < http://hdl.handle.net/2268/207441 > .

[12] Li H, Hu D, Wang M, Dai Y. Off-design performance analysis of Kalina cycle for low temperature geothermal source. Appl Therm Eng 2016;107:728-37. http://dx.doi. org/10.1016/j.applthermaleng.2016.07.014.

[13] Song J, Gu C-w, Ren X. Parametric design and off-design analysis of organic Rankine cycle (ORC) system. Energy Convers Manage 2016;112(March):157-65. http://dx.doi.org/10.1016/j.enconman.2015.12.085. URL < http://www. sciencedirect.com/science/article/pii/S0196890416000157>.

[14] Möller A, Gullapalli VS. System cost and efficiency optimization by heat exchanger performance simulations. Energy Procedia 2017;119:459-65. http://dx.doi.org/10. 1016/j.egypro.2017.07.087. URL < https://doi.org/10.1016/j.egypro.2017.09. $228>$

[15] Gullapalli VS. Modeling of brazed plate heat exchangers for ORC systems. Energy Procedia 2017;129:443-50. http://dx.doi.org/10.1016/j.egypro.2017.09.207.

[16] Ziviani D, Woodland B, Georges E, Groll E, Braun J, Horton W, et al. Development and a validation of a charge sensitive organic Rankine cycle (ORC) simulation tool. Energies 2016;9(6):389. http://dx.doi.org/10.3390/en9060389. URL < http:// www.mdpi.com/1996-1073/9/6/389>.

[17] Liu L, Zhu T, Ma J. Working fluid charge oriented off-design modeling of a small scale organic Rankine cycle system. Energy Convers Manage 2017;148:944-53. http://dx.doi.org/10.1016/j.enconman.2017.06.009.

[18] Rossi TM. Detection, diagnosis, and evaluation of faults in vapor compression equipment [Phd thesis]. Purdue University; 1995. URL $<$ http://docs.lib.purdue. edu/dissertations/AAI9622762/>.

[19] Grodent M. Contribution à l'étude des composants de systèmes frigorifiques: modélisation en régime stationnaire et validation expérimentale. Application des modèles développés à l'étude d'un système bisplit [Ph.D. thesis]. University à Liège; 1998.

[20] Cuevas Barraza C. Contribution to the modelling of refrigeration systems [Phd 
thesis]. University of Liège; 2006

[21] Farzad M, O'Neal DL. The effect of void fraction model on estimation of air conditioner system performance variables under a range of refrigerant charging conditions. Int J Refrig 1994;17(2):85-93. http://dx.doi.org/10.1016/0140-7007(94) 90048-5.

[22] Bendapudi S, Braun JE, Groll EA. A comparison of moving-boundary and finitevolume formulations for transients in centrifugal chillers. Int J Refrig 2008;31(8):1437-52. http://dx.doi.org/10.1016/j.ijrefrig.2008.03.006.

[23] Desideri A, Dechesne B, Wronski J, Broek MVD, Sergei G, Lemort V, et al. Comparison of moving boundary and finite-volume heat exchanger models in the Modelica language. Energies 2016:1-17.

[24] Grald EW, MacArthur J. A moving-boundary formulation for modeling time-dependent two-phase flows. Int J Heat Fluid Flow 1992;13(3):266-72. http://dx.doi. org/10.1016/0142-727X(92)90040-G.

[25] Alobaid F, Mertens N, Starkloff R, Lanz T, Heinze C, Epple B. Progress in dynamic simulation of thermal power plants. Prog Energy Combust Sci 2017;59:79-162. http://dx.doi.org/10.1016/j.pecs.2016.11.001.

[26] Bell IH, Wronski J, Quoilin S, Lemort V. Pure and pseudo-pure fluid thermophysical property evaluation and the open-source thermophysical property library CoolProp. Ind Eng Chem Res 2014:53(6):2498-508.

[27] Dickes R, Ziviani D, de Paepe M, van den Broek M, Quoilin S, et al. ORCmKit: an open-source library for organic Rankine cycle modelling and analysis. In: Proceedings of ECOS 2016, Portoroz (Solvenia); 2016. < http://hdl.handle.net/ 2268/198722>

[28] Dickes R, Dumont O, Declaye S, Quoilin S, Bell I, Lemort V. Experimental in vestigation of an ORC system for a micro-solar power plant. In: Proceedings of the 22nd international compressor engineering at Purdue, Purdue (USA); 2014. < http://hdl.handle.net/2268/170508 >

[29] Georges E, Declaye S, Dumont O, Quoilin S, Lemort V. Design of a small-scale organic Rankine cycle engine used in a solar power plant. Int J Low-Carbon Technol 2013;8:34-41. http://dx.doi.org/10.1093/ijlct/ctt030. URL < http://hdl.handle. net/2268/149519>

[30] Bryszewska-Mazurek A, Świeboda T, Mazurek W. Performance analysis of a solarpowered Organic rankine cycle engine. J Air Waste Manage Assoc 2011;61(1):3-6. http://dx.doi.org/10.3155/1047-3289.61.1.3.

[31] Baral S, Kim D, Yun E, Kim K. Experimental and thermoeconomic analysis of smallscale solar organic Rankine cycle (SORC) system. Entropy 2015;17(4):2039-61. http://dx.doi.org/10.3390/e17042039. URL < http://www.mdpi.com/1099-4300/ $17 / 4 / 2039 />$.

[32] Orosz M, Mueller A, Quoilin S, Hemond H. Small scale solar ORC system for distributed power in Lesotho. In: 29th ISES biennial solar world congress 2009, ISES 2009, vol. 2; 2009. p. 1042-8. < http://www.scopus.com/inward/record.url? eid = 2-s2.0-84873835908\&partnerID = tZOtx3y1 >

[33] Electratherm. ElectraTherm ORC - Primer Series 4000 Green Machine; 2012 $<$ https://electratherm.com/orc-knowledge-center-2/what-is-a-power-plusgenerator/ $>$

34] Enogia. ENO ORC units datasheet; 2017. < http://enogia.com/product.php >

[35] InfinityTurbine. IT50 ORC unit - datasheet; 2017. < http://www.infinityturbine. com/it50.html >

[36] Rank. Rank LT/MT/HT/HTC units; 2017. < http://www.rankweb.es/ >

[37] Bell IH, Quoilin S, Georges E, Braun JE, Groll EA, Horton TW, et al. A generalized moving-boundary algorithm to predict the heat transfer rate of counterflow heat exchangers for any phase configuration. Appl Therm Eng 2015;79:192-201. URL $<$ http://linkinghub.elsevier.com/retrieve/pii/S1359431114011570>.

[38] Martin H. A theoretical approach to predict the performance of chevron-type plate heat exchangers. Chem Eng Process 1996;35(4):301-10.

[39] Wanniarachchi SA, Ratnam U, Tilton BE, Dutta-Roy K. Approximate correlations for chevron-type plate heat exchangers. In: Proceedings of the 30th national heat transfer conference, New York; 1995. p. 145-1.

[40] Ayub ZH. Plate heat exchanger literature survey and new heat transfer and pressure drop correlations for refrigerant evaporators. Heat Transf Eng 2003;24(5):3-16. http://dx.doi.org/10.1080/01457630304056.

[41] Amalfi RL, Vakili-Farahani F, Thome JR. Flow boiling and frictional pressure gradients in plate heat exchangers. Part 2: comparison of literature methods to database and new prediction methods. Int J Refrig 2016;61:185-203. http://dx.doi.org/ 10.1016/j.ijrefrig.2015.07.009.

[42] Han D-H, Lee K-J, Kim Y-H. Experiments on the characteristics of evaporation of $\mathrm{R} 410 \mathrm{~A}$ in brazed plate heat exchangers with different geometric configurations. Appl Therm Eng 2003;23:1209-25. http://dx.doi.org/10.1016/S1359-4311(03) 00061-9.

[43] Cooper MG. Saturation nucleate pool boiling - a simple correlation. Inst Chem Eng Symp Ser 1984;86:785-93. http://dx.doi.org/10.1016/B978-0-85295-175-0. 50013-8. URL < http://www.sciencedirect.com/science/article/pii/ B9780852951750500138>.

[44] Longo GA, Righetti G, Zilio C. A new computational procedure for refrigerant condensation inside herringbone-type Brazed Plate Heat Exchangers. Int J Heat Mass Transf 2015;82:530-6. http://dx.doi.org/10.1016/j.ijheatmasstransfer.2014. 11.032.

[45] Han DH, Lee KJ, Kim YH. The characteristics of condensation in brazed plate heat exchangers with different chevron angles. J Kor Phys Soc 2003;43(1):66-73. http:// dx.doi.org/10.1016/S1359-4311(03)00061-9.

[46] Shah MM. A general correlation for heat transfer during film condensation inside pipes. Int J Heat Mass Transf 1979;22(4):547-56. http://dx.doi.org/10.1016/00179310(79)90058-9.

[47] VDI Heat Atlas. 2nd ed. Berlin, Heidelberg: Springer-Verlag.

[48] Cavallini A, Col DD, Doretti L, Matkovic M, Rossetto L, Zilio C, et al. Condensation in horizontal smooth tubes: a new heat transfer model for heat exchanger design. Heat Transf Eng 2006;27(8):31-8. http://dx.doi.org/10.1080/ 01457630600793970. URL < http://www.tandfonline.com/doi/abs/10.1080/ $01457630600793970>$

[49] Wang C-C, Chi K-Y, Chang C-J. Heat transfer and friction characteristics of plain finand- tube heat exchangers, part II: correlation. Int J Heat Mass Transf 2000;43(15):2693-700. http://dx.doi.org/10.1016/S0017-9310(99)00333-6.

[50] Eldeeb R, Aute V, Radermacher R. A survey of correlations for heat transfer and pressure drop for evaporation and condensation in plate heat exchangers. Int $\mathrm{J}$ Refrig 2016;65:12-26. http://dx.doi.org/10.1016/j.ijrefrig.2015.11.013.

[51] García-Cascales JR, Vera-García F, Corberán-Salvador JM, Gonzálvez-Maciá J. Assessment of boiling and condensation heat transfer correlations in the modelling of plate heat exchangers. Int J Refrig 2007;30(6):1029-41. http://dx.doi.org/10. 1016/j.ijrefrig.2007.01.004

[52] Waltz RA, Morales JL, Nocedal J, Orban D. An interior algorithm for nonlinear optimization that combines line search and trust region steps. Math Program 2006;107(3):391-408. http://dx.doi.org/10.1007/s10107-004-0560-5.

[53] Rice CK. Effect of void fraction correlation and heat flux assumption on refrigerant charge inventory predictions. In: ASHRAE transactions, vol. 93, New York (USA); 1987. p. 341-67.

[54] Woldesemayat MA, Ghajar AJ. Comparison of void fraction correlations for different flow patterns in horizontal and upward inclined pipes. Int J Multiph Flow 2007;33(4):347-70. http://dx.doi.org/10.1016/j.ijmultiphaseflow.2006.09.004.

[55] Zivi SM. Estimation of steady-state steam void-fraction by means of the principle of minimum entropy production. J Heat Transf 1964;86(2):247-51. http://dx.doi.org/ 10.1115/1.3687113. URL < http://heattransfer.asmedigitalcollection.asme.org/ article. aspx? articleid $=1433167>$.

[56] Lockhart RW, Martinelli RC. Proposed correlation of data for isothermal two-phase two-component flow in pipes.pdf. Chem Eng Prog 1949;45(1):39-48.

[57] Premoli A, Francesco D, Prina A. A dimensional correlation for evaluating twophase mixture density. La Termotecnica 1971;25:17-26.

[58] Hughmark G. Holdup in gas liquid flow. Chem Eng Prog 1962;58(4):62-5.

[59] Lemort V, Quoilin S, Cuevas C, Lebrun J. Testing and modeling a scroll expander integrated into an Organic Rankine Cycle. Appl Therm Eng 2009;29(14-15):3094-102. http://dx.doi.org/10.1016/j.applthermaleng.2009.04. 013.

[60] Dickes R, Dumont O, Legros A, Quoilin S, Lemort V. Analysis and comparison of different modeling approaches for the simulation of a micro-scale organic Rankine cycle power plant. In: Proceedings of ASME -ORC 2015; 2015.

[61] Landelle A, Tauveron N, Revellin R, Haberschill P, Colasson S, Roussel V. Performance investigation of reciprocating pump running with organic fluid for organic Rankine cycle. Appl Therm Eng 2017;113:962-9. http://dx.doi.org/10. 1016/j.applthermaleng.2016.11.096.

[62] Brent RP. Algorithms for minimization without derivatives; 2002. 